\title{
FRANCOS, AQUITANOS Y VASCONES. TESTIMONIOS ARQUEOLÓGICOS AL SUR DE LOS PIRINEOS
}

\author{
POR \\ A. AZKÁRATE GARAI-OLAUN \\ Universidad del Pais Vasco (Ärea de Arqueologia).Vitoria
}

\begin{abstract}
RESUMEN
Este artículo constituye un breve avance de las investigaciones que, desde hace algunos años, viene efectuando el autor sobre la época tardoantigua en el área de los Pirineos más occidentales. El descubrimiento en tierras alavesas y navarras de dos necrópolis de los siglos vi y vil, con un número de armas digno de mención y con rituales, depósitos y ajuares funerarios que nos remiten no a un contexto cultural hispanovisigodo sino al norte de los Pirineos, permite abrir un debate que replantee las interpretaciones historiográficas actuales para este periodo.
\end{abstract}

\section{SUMMARY}

This article is a brief advance of the archaeological investigations that the author is making about the Late Antiquity age on the Western Pyrenees. The finding in Alava and Navarre of two necropolis of the VIth and VIIth centuries, with a worth mentioning number of weapons and with funerary rituals and offerings that refer not to a Hispanic-Wisigothic cultural context but to a north Pyrennean one (of the Aquitainne area to be exact), allows to open a discussion to restate the actual historiographic interpretations for this period.

Se ha escrito muchas veces que la tardoantigüedad constituye, dentro de la historiografia europea, uno de los períodos más oscuros y menos conocidos. Y sí puede, en efecto, afirmarse que hay mucha verdad en ello, la hay mucho más cuando nos referimos a la región de los Pirineos Occidentales y sus aledaños, ámbito polémico como pocos y con unas peculiaridades especificas que lo han convertido en objeto de enconadas discusiones en las que, frecuentemente, se han entrecruzado intereses muy diversos.

Sucede también que la propia escasez de las fuentes nos obliga en ocasiones a caer de forma reiterada en lugares comunes de la historiografía de este período, abusando de temas tan recurrentes como la presunta vasconización de territorios distintos a los del solar vascón de 
época clásica, las campañas de los monarcas visigodos contra los territorios peninsulares septentrionales con la polémica interpretación de algunos topónimos recogidos en los cronicones-. la actitud de los vascones frente al poder politico de Toledo, su mayor o menor grado de independencia o paganismo, etc., todo ello acompañado de los acostumbrados epítetos de ferocidad, barbarie e incultura que califican desde hace milenio y medio a aquellos habitantes del entorno pirenaico. Hay, sin duda, estudios muy serios, pero resulta dificil abandonar la sensación de que es poco, muy poco, lo que todavia sabemos sobre todo ello.

No conviene olvidar, finalmente, el indudable peso de las llamadas «historiografias nacionales" a la hora de proponer o defender determinadas interpretaciones. Los Pirineos en época tardoantigua, y con la excepción de su parte más oriental, han sido vistos reiteradamente a partir de Vouillé como una pantalla que separaba nítidamente - salvo esporádicas incursiones en uno u otro sentido- - un horizonte septentrional «franco" de otro meridional "visigodo» en una concepción del pasado que topaba, sin embargo, con el enojoso problema de los vascones y sobre quienes no se ha podido consensuar ni su ubicuidad ni las razones de su comportamiento. Las opiniones, como cabia esperar, son para todos los gustos.

En este marco historiográfico, la aparición de las necrópolis de Aldaieta (Nanclares de Gamboa, Alava) y Buzaga (Elorz, Navarra) constituye una verdadero hito para el periodo tardoantiguo. Su excepcional importancia radica precisamente en su carácter de descubrimientos no previstos por la historiografia tradicional y que cuestionan determinados puntos de vista sólidamente cimentados durante largos decenios al reflejar en sus materiales una estrecha relación con contextos culturales norpirenaicos. Aldaieta y Buzaga, además, revalorizan un yacimiento conocido desde antiguo: la necrópolis de Pamplona, denominada franca por unos y visigoda por otros.

Si los materiales de Pamplona han resultado discutidos se debe, en parte, al carácter mixtificado de la propia necrópolis, con elementos tardorromanos, hispanovisigodos, merovingios e, incluso, islámicos. Esta diversificación cultural, su larga perduración en el tiempo y el hecho de que la ciudad de Pamplona constituyera un punto de enorme importancia estratégica, apetecido por unos y por otros, ha motivado que los aspectos norpirenaicos de la necrópolis hayan encontrado explicación en las incursiones que determinados monarcas merovingios realizaron al sur de los Pirineos. En este sentido, lo norpirenaico ha sido visto siempre como algo esporádico y circunstancial que hubo de dejar alguna huella, obviamente, pero nada, en suma, que fuera estable o definitivo en una Península Ibérica que, no sin cierta complacencia, se ha querido presentar unificada religiosa y politicamente bajo el poder toledano.

Los recientes descubrimientos de Buzaga y Aldaieta vienen, como decimos, a complicar los puntos de vista tradicionales. Ya no se trata de elementos aislados, sino la existencia de poblaciones estables lo que obligará a abrir un debate serio durante los próximos años '. El texto que ahora presentamos no es, obviamente, más que un brevísimo avance de las investigaciones que estamos llevando a cabo desde hace algún tiempo y que esperamos dar a conocer en el plazo máximo de dos o tres años. Antes de entrar en materia nos gustaria, sin embargo, realizar una observación que consideramos obligada. Siempre hemos sido partidarios de huir de la tentación arqueográfica procurando contextualizar históricamente los datos arqueológicos. Esta

' Asi lo proponiamos en un reciente seminario celebrado en Italia en 1991: A. Azkárate, The Western Pyrenees during the Late Antiquity. Reflections for a reconsideration of the issue, /l Territorio tra tardoantico e altomedioevo. Metodi di indagine e risultati. Biblioteca di "Archeología Medievale», Firenze, 1992, págs. 179-191. 
vez, no obstante, nos hemos sentido excusados por dos motivos: por la presencia, en primer lugar, del artículo de K. Larrañaga complementario al nuestro. $\mathrm{Y}$, en segundo lugar, porque nuestro objetivo fundamental es el de dar a conocer la existencia de unos testimonios arqueológicos que apuntan inequívocamente al norte de los Pirineos y no el de reflexionar históricamente sobre este hecho, asunto que, como es obligado, habrá de ser abordado en su momento.

\section{ALGUNOS APUNTES SOBRE LA ARQUEOLOGIA FRANCO-AQUITANA}

Desde que C. Barrière-Flavy primero ${ }^{2}, \mathrm{~N}$. Aberg algo más adelante ${ }^{3} \mathrm{y}$, más recientemente E. James ${ }^{4}$ - entre otros - efectuaron sus trabajos sobre los ajuares funerarios de época tardoantigua en el sudoeste francés, se ha venido identificando una "facies» arqueológica definida como "aquitana», diferenciable de otra calificada como "septentrional», "nórdica» o "franca".

C. Barrière-Flavy habia concedido un origen visigótico a estas peculiaridades meridionales, siendo posteriormente rebatido por N. Aberg, que - ciñéndonos ahora al capítulo de las guarniciones de cinturón- prefirió considerarlas como producto de una población nativa que habria recibido influjos germánicos, de manera que sus broches de cinturón constituirían una mixtificación de formas francas y ornamentación quitano-mediterránea ${ }^{5}$.

E. James, profundizando en este punto de vista, enfatizó aun más la existencia de unos caracteres propios del sudoeste de la Galia que llegaría a influir, incluso, al norte del Loira ${ }^{\circ}$. "Los arqueólogos... - llegaba a afirmar-llevan demasiado tiempo acostumbrados a considerar a los francos como los árbitros del gusto y de la cultura, pensando siempre que las costumbres merovingias se extendieron del norte al sur. Hay historiadores que llevan algún tiempo defendiendo el movimiento en el otro sentido (...). Quizás una valoración de los broches aquitanos nos llevara a concluir que también e el campo artístico tenían algo que aportar los hombres del sudoeste al resto de la Galia»? .

Trabajos más recientes han efectuado algunas correcciones a los postulados de E. James. P. Perin, sin dejar de reconocer el valor del trabajo de este autor, matizó, por ejemplo, algunas de sus hipótesis, defendiendo la evolución conjunta de todos los broches del sudoeste con las demás guarniciones de cinturón del resto de la Galia, a pesar de la inequívoca personalidad de los ejemplos aquitanos del siglo vil y de la particular eclosión que sufrieron en esta centuria ${ }^{\mathrm{x}}$.

${ }^{2}$ C. Barriere-Flavi, Etude sur les sépultures barbares du midi et de l'ouest de la France. Industrie wisigothique, Toulouse, 1892. ID.: Les arts industriels des peuples barbares de la Gaule du Vème au VIIlème siècle, Toulouse, 1901.

${ }^{3}$ N. Aberg, The Orient and the Occident in the art of the seventh century, III, Stockholm, 1947, especialmente págs. 58-64.

${ }^{4}$ E. James, The Merovingian Archaeology of South-West Gaul, Oxford, 1977 (BAR 25), 2 vol.

5 N. Aberg, The Orient and the Occident, cit. III, págs. 44-48.

${ }^{6}$ E. James, The Merovingian Archaeology, cit. págs. 97 y ss.

7 Ibidem, pág. 151.

* P. Perin, Compte-rendu de l'ouvrage d'E. James: The Merovingian Archaeology of South-West Gaul, en M. Larrieu et alii, La nécropole mérovingienne de la Turraque, Beaucaire-sur-Baise (Gers), Toulouse, 1982 Annexe 4, págs. 277-287. 
Más recientemente, S. Lerenter ha continuado en la misma linea que P. Perin, efectuando importantes mejoras en las tablas tipológicas de E. James".

Entre las particularidades, básicamente decorativas, que recoge James para los broches de cinturón del sudoeste de la Galia, cabe destacar las siguientes: a) división del campo ornamental en paneles transversales ${ }^{10} ; h$ ) utilización del puntillado tanto para decorar los fondos de las placas como para ejecutar los motivos lineales ". Esta última sería, para E. James, "probablemente la cuestión decorativa más característica de las hebillas aquitanas y un elemento más que separa el grupo de otros estilos de trabajo en metal durante el periodo merovingion; $c$ ) presencia de ornamentación zoomorfa, fundamentalmente cuadrúpedos, distinta de la que se conoce en el ciclo burgundio ${ }^{12} ; d$ ) decoración geométrica a base de medallones, motivos cuadrilobulados, entrelazados, semicírculos dobles apoyando en el borde de la hebilla ${ }^{13}$, etc. A estas peculiaridades ornamentales habría que añadir otras de carácter técnico, como el baño de estaño que recubre estas piezas dándoles un aspecto brillante y plateado y su realización mayoritaria en bronce con apenas presencia de ejemplares de hierro con damasquinados, tan caracteristicos de la Galia septentrional.

Tras esta brevísima aproximación a una parte de la arqueología franco-aquitana, analicemos ahora algunos de los materiales conocidos al sur de los Pirineos. Veamos, en efecto, si existen motivos para la reticencia o si, tal y como pensamos, resulta indudable el carácter "extrapeninsular» y "norpirenaico» de algunos elementos que no pueden considerarse ya hallazgos aislados o minoritarios, sino reflejo de una «realidad no prevista» por la historiografia tradicional y para los que habrá que buscar una explicación satisfactoria.

\section{LA NECRÓPOLIS DE PAMPLONA}

La necrópolis de Pamplona es conocida desde antiguo. Excavada en 1895 por F. Ansoleaga y J. Iturralde y Suit, sus materiales fueron dados a conocer primero por el propio Ansoleaga ${ }^{14}$,

${ }^{9} \mathrm{~S}$. Lerenter, Les plaques-boucles mérovingiennes en bronce de type aquitain. Nouvelle approche typologique et chronologique. Mémoire de maîtrisse dactylographié, Univ. de Paris I, 1987; ID.: Nouvelle approche typologique des plaques-boucles mérovingiennes en bronce de type aquitain, Gallo-romains, wisigoths et francs en Aquitaine. Septiembre et Espagne. (Ed. P. Perin) Actes des Vlle Journèes Internationales d'Archéologie Mérovingienne (Toulouse, 1985), Rouen, 1991, págs. 225-257.

11" Ya señalada por N. Aberg (CIT., III, pág. 48). Cfr. E. James, The Merovingian Archaeology, cit. pág. 119 .

" E. James, The Merovingian Archaeology, cit. pág. 120.

$12 \mathrm{Ibidem}$, pág. 123. Cfr. una reciente aportación al respecto de S. Lerenter, Les motifs animaliers des plaques-boucles en bronze de type aquitain, Actes des Xe Journées Internationales d'Archéologie Mérovingienne (Metz, 1988), Sarreguemines, 1989, págs. 55-61.

${ }^{13}$ Según James, este rasgo constituirá el motivo geométrico más importante. Definido como «typical Aquitanian semi-circular arcading» (pág. 375), constituye «un motivo prácticamente universal de las hebillas aquitanas, siendo uno de los más utilizados como diseño para un borde o para rellenar un espacio (...). Que yo sepa, aparecen exclusivamente en la Galia romana, en la zona de los Pirineos franceses, justo al sur de Toulouse: en Bagnères-de-Luchon, Saint-Pé, Mayrège, Tarbes y Blagnac. Por lo tanto, aparece en monumentos de principios o mediados del Imperio, no lejos de la zona en la que debió de nacer el estilo aquitano» (The Merovingian Archaeology, cit. pág. 140).

${ }^{14} \mathrm{~F}$. Ansoleaga, El cementerio franco de Pamplona, Boletin de la Comisión de Monumentos de Navarra, Año 1916, números 25, 26 y 27. 
recogidos más tarde por $\mathrm{H}$. Zeiss ${ }^{15}$ y publicados por última vez por $\mathrm{M}$. A. Mezquririz ${ }^{16}$. Los comentarios posteriores sobre el carácter de los materiales de esta necrópolis, sin embargo, han sido muy diversos, como pronto veremos.

Según se deduce de las publicaciones mencionadas, la necrópolis de Pamplona ofreció un centenar de sepulturas de lajas en cuyo interior el cadáver del difunto fue depositado directamente sobre el suelo. Los enterramientos, alineados en dirección O-E (cabeza a poniente y pies a oriente), dispuestos sin una regularidad aparente dentro del espacio cementerial, ofrecieron un importante conjunto de objetos arqueológicos conservados actualmente en el Museo de Navarra y cuya ubicación original dentro de cada enterramiento nos resulta desconocida. Son bastantes, como decimos, los elementos tanto de ajuar personal como de depósito estrictamente funerario ${ }^{17}$ recuperados por Ansoleaga e Iturralde y Suit. Entre los primeros habría que señalar un lote de armas - seis puntas de lanza, tres "scramasex" o espadas de un solo filo, dos puntas de flecha, casi una veintena de elementos pertenecientes a guarniciones de cinturón (hebillas, agujas escutiformes, broches con placa articulada, broches con placa rígida, etc.), dos fragmentos de fibulas (romano-tardias probablemente), brazaletes, zarcillos, cincuenta y dos sortijas de plata, bronce o hierro, etc. Entre los segundos se recogen ocho recipientes derámicos de tipología diversa, dos trientes de oro de Suiutila acuñados uno en Saldaña ( $\mathrm{Pa}$ lencia) y otro en Zaragoza, una defensa de fabali perforada para su uso como colgante y dos láminas de sílex ${ }^{18}$.

Todos estos materiales, como decíamos, han sido objeto de diversos comentarios, muchos de ellos contradictorios, que hacen que la necrópolis de Pamplona merezca, en opinión nuestra, un nuevo estudio a la luz de los datos que poseemos en la actualidad. F. Ansoleaga se había referido a un cementerio "franco" ${ }^{19}$. H. Zeiss había defendido también su carácter "más merovingio que visigodo" ${ }^{20}$. M. A, sin embargo, prefirió considerarlo "visigodo». Nos parece importante señalar, no obstante, que esta autora se decide en favor de tal adjetivación "por la datación de los hallazgos más que por el carácter étnico de la población inhumada» ${ }^{21}$ que no sería ni franca ni visigoda sino vascona, a pesar de reconocer que los ajuares de Pamplona «responden al inventario habitual de los cementerios merovingios» ${ }^{22}$.

Llevaba razón L. A. García Moreno al referirse a los «discutidísimos» testimonios arqueo-

${ }^{15}$ H. Zeiss, Die Grabfunde aus dem Spanischen Westgotenreich. Berlín-Leipzig, 1934.

${ }^{16}$ M. A. Mezquiriz, Necrópolis visigoda de Pamplona, Principe de Viana, 98-99, 1965, págs. 170ss.

${ }^{17}$ Sobre la necesidad de diferenciar aquellos objetos depositados en la tumba como manifestación de determinadas creencias de carácter escatológico («depósito funerario»), de aquellos otros que constituyen las pertenencias personales del difunto, instransferibles por herencia («ajuar personal»), cfr. B. Young, Paganisme, christianisation el rites funéraires mérovingiens, Archéologie Médiévale, VII, 1977, págs. 5ss. (47-54); A. Azkárate, Algunas consideraciones sobre la Arqueología de Época Germánica en Euskal Herria, Munibe (Antropologia-Arqueologia), 42, 1990, págs. 345 ss (348-349).

${ }^{18}$ Al desconocer su contexto arqueológico, siempre resultará difícil saber con certeza si la defensa del jabali y las lascas de silex tuvieron un carácter usual o apotropaico.

${ }^{19}$ No entramos a valorar el periodo inmediatamente anterior (época tardorromana) o posterior a los siglos vi y VII (J. Navascués, Rectificaciones al cementerio hispanovisigodo de Pamplona. Nuevas huellas del Islam próximas a los Pirineos, Principe de Viana, 142-143, 1976, págs. 118ss).

${ }^{20} \mathrm{H}$. Zeiss, Los elementos de las artes industriales visigodas, cit. pág. 159.

${ }^{21}$ M. A. Mezquíriz, Necrópolis visigoda, cit. págs. 107-109.

${ }^{22} \mathrm{Ibidem}$, pág. 131. Además de los materiales recuperados por Ansoleaga e Iturralde y Suit, existen algunos otros procedentes de diversas intervenciones realizadas en la ciudad durante la segunda mitad 
lógicos de Pamplona ". Creemos sin embargo que, aunque discutidos, de lo que no cabe dudar es de la inequivoca influencia norpirenaica en este yacimiento y de que, todo ello, refleja unas relaciones entre ambos lados de los Pirineos muy superiores a las que ha admitido tradicionalmente la historiografia española y a las que han imaginado, incluso, autores tan cualificados en este tema como E. James ${ }^{24}$ o M. Rouche ${ }^{25}$.

Sin espacio suficiente, en el marco de este trabajo, para un análisis exhaustivo de todos los materiales recuperados en esta necrópolis - análisis que dejamos para una ocasión próximanos fijaremos ahora en algunos de los elementos pertenecientes a las guarniciones de cinturón, caracteristicos, como veremos, de un contexto cultural no visigodo.

1. El primer ejemplar es un broche de cinturón completo (fig. 1, a) 2th $^{\text {th }}$ que consta de una placa articulada trapecial con tres botones o remaches y dos espigas para su articulación con la hebilla, arriñonada y con aguja de base escutiforme. No resulta fácil encontrar paralelos de esta pieza. Cita M. A. Mezquiriz ${ }^{27}$ un ejemplar muy semejante procedente de la necrópolis de Estagel. H. Zeiss la considera, junto con la siguiente, como únicas en la Peninsula y dependientes de prototipos francos ${ }^{2 x}$. Morfológicamente no responden a ninguna de las categorías establecidas para el mundo aquitano, sino más bien a los broches de placa rectangular o trapecial con tres o cuatro remaches (tipo 59 de Perin) propios del mundo «septentrional» o "francon, aunque estos últimos estén realizadas en hierro - con damasquinados en algún caso-y nuestro ejemplar, por el contrario, sea enteramente de bronce. La decoración, en cambio, sí que es plenamente aquitana, con una línea ondulada en el centro de la placa, flanqueada a ambos lados por un trenzado de giros mal trazados y casi angulosos. Trenzados similares pueden contemplarse en sendas piezas de los museos de Périguex ${ }^{29}$, Agen ${ }^{30}$, Museo de la sociedad arqueológica de Charente, en Angoulême ${ }^{31}$, Museo Ingres, en Montauban ${ }^{32}$, etc.

2. El segundo ejemplar de la necrópolis de Pamplona que pasamos a comentar es un broche de cinturón del que se conservan únicamente la placa y la aguja (fig. 1, b). Morfológicamente resulta similar al caso anterior, aunque lo diferencian de él los dos «picos» que se

de este siglo. Algunos de ellos - campañas de 1956 y 1965 - apuntan claramente al mismo contexto cronológico y cultural que venimos comentando. Véase, a ese respecto, M. A. Mezquiriz, Pompaelo I. Campaña de 1956, Pamplona, 1958, págs. 295-296, fig. 138 y, de la misma autora, Pompaelo II. Pamplona 1978, págs. 15 y 50 (referencias a la campaña de 1965) y, sobre todo, págs. 77-79, fig. 39 y lam. XXVII.

${ }^{23}$ L. A. García Moreno, Algunas cuestiones de Historia navarra en la antigüedad tardia (siglos vvii), Primer Congreso General de Historia de Navarra, Principe de Viana, 1988, pág. 413.

${ }^{24}$ E. James, Septimania and its Frontier. An Archaeological Approach, Visigothic Spain. New Approaches, Oxford, 1980, págs. 223ss (228).

${ }^{25} \mathrm{M}$. Rouche, Les relations transpyrénéennes du $\mathrm{V}^{\mathrm{e}}$ au $\mathrm{VIII}{ }^{\mathrm{e}}$ siècle, Les communications dans la Péninsule Ibérique au Moyen-Age, Actes du Colloque de Pau, 28-29 mars, 1980, París, 1981.

${ }^{26}$ Queremos agradecer a M. A. Mezquiriz, directora del Museo de Navarra, la cesión de las fotografias que ilustran este trabajo.

${ }^{27}$ M. A. Mezquiriz, Necrópolis de Pamplona, cit. pág. 113.

${ }^{2 \times} \mathrm{H}$. Zeiss, Los elementos de las artes industriales visigodas, cit. pág. 149.

${ }^{29}$ E. James, The Merovingian Archaeology, cit. pl. 132.

${ }^{30}$ Ibidem, pl. 131 y 139 (procedentes de Lourdins, Lot-et-Garonne), pl. 159 (procedente de Eymetsur-Drop. Dordogne).

31 Ibidem, pl. 156.

32 Ibidem, pl. 138. (procedentes de Grezás, Tarn-et Garonne). 

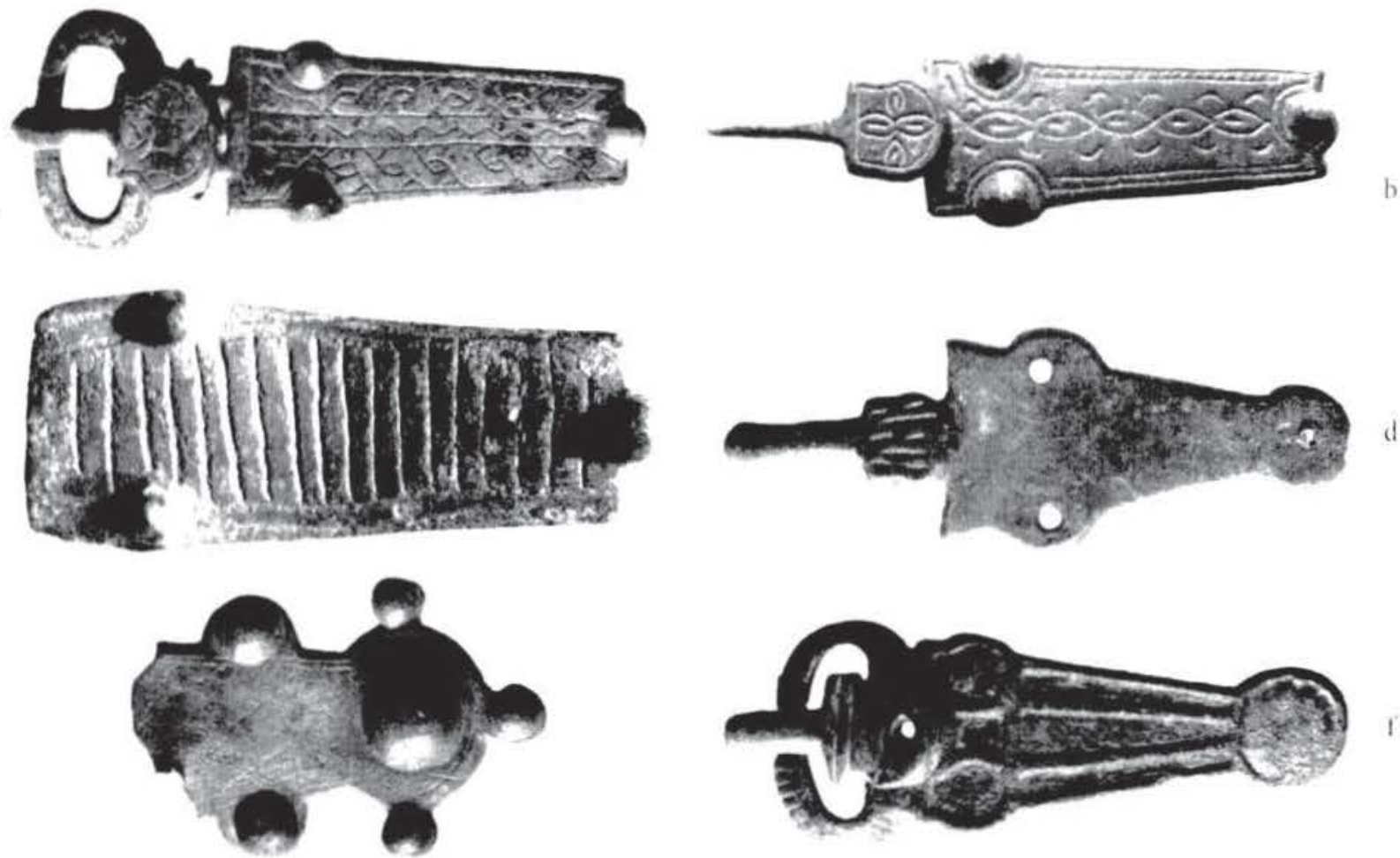

Figura 1.-Broches y placas de cinturón procedentes de la necrópolis de Pamplona.

insinuan en el extremo opuesto al del engarce con la hebilla y que lo aproximan al grupo IB de James ( Beaked» Buckle-Plates), si bien es más estilizado que lo que acostumbran a ser los ejemplares caracteristicos de este grupo aquitano.

3. El siguiente ejemplar (fig. 1, c) es completamente peculiar tanto por su decoración (lineas transversales ocupando todo el campo de la placa), como por su morfologia. Probablemente se trate de una contraplaca.

4. El cuarto de los broches de cinturón que comentamos (fig. 1, d) responde a una de las piezas más caracteristicas del mundo merovingio. Se trata, en concreto, del tipo 64 , I de Perin ${ }^{13}$ (grupo II de James, tipo D13 de Lerenter) y que básicamente conforma una placa triangular con tres apéndices circulares sobre el perfil de la pieza, y dos espigas para su articulación con la hebilla. Los paralelos son múltiples it, fechándose todos ellos en la primera mitad del siglo vII. En nuestro ejemplar, los apéndices circulares carecen, por pérdida, de los botones o remaches que descansan sobre ellos.

5. El siguiente ejemplar constituye, una vez más, una pieza caracteristica de este mundo (fig I, e). Según Mezquiriz "corresponde plenamente a un grupo de hallazgos franceses, uno

${ }^{31}$ P. Perin, La datation des tomhes mérovingiennes. Historique-Mèthodes-Appications, Genève, 1980.

${ }^{34}$ Véanse, a modo de ejemplo, los ejemplares procedentes de la necrópolis aquitana de La Turraque: M. Larrieu et alii, La nécropole mérovingienne de La Turraque, cit. págs. 134-135. Cfs. S. Lerenter, Les motifs animaliers de plaques-boucles en bronze de type aquitain, Actes des Xe Journées Internationales d'Archéologie Mérovingienne, 1989, págs. 55-61. 
de ellos procedente de Nolet que presenta una extraordinaria semejanza, incluso en la decoración de un animal incison ${ }^{35}$. Tipológicamente, sin embargo, el fragmento de placa de Pamplona nada tiene que ver con el paralelo de Nolet - claro ejemplo del grupo IB de James - y si, en cambio, con el grupo IV de este mismo autor que engloba unas piezas características, con placa trapezoidal de tres pares de botones o remaches en los laterales y un gran botón o cabeza de remache en el pie rodeado de otros tres más pequeños (Lerenter, tipo D22). Estos broches de diez botones poseen un notable interés. Su inclusión por James dentro de los broches aquitanos en función de sus motivos iconográficos ${ }^{36}$ fue criticado por Perin ${ }^{37}$, quien, recogiendo algunos trabajos recientes, prefirió ubicar su centro de gravedad y, probablemente también, sus centros de producción, en el Loira medio y en la Baja Normandia ${ }^{3 \times}$. Las placas normandas han sido fechadas por $\mathrm{Cl}$. Lorren a fines del siglo vII o comienzos del $\mathrm{VII}^{34}$.

6. El sexto de los ejemplares (fig. 1, f) nos traslada, una vez más, al norte de los Pirineos. Se trata de un broche de cinturón de placa rígida triangular y hebilla arriñonada, dos apéndices circulares alveolados en su base enmarcando una pequeña concavidad cuadrangular, un apéndice circular alveolado en su vértice y tres cavidades alargadas ocupando el espacio central. Todos estos compartimentos acogían la pasta del esmalte, hoy desaparecida, siendo una técnica frecuente en el mundo aquitano ${ }^{40}$. Este tipo de ejemplares constituyen, probablemente, una evolución de los broches "mediterráneos» del siglo vi, fundidos en una pieza y con unos apéndices "en chefs d'oisseaux à bec crochu», pudiendo ser datados a comienzos de la séptima centuria $^{+1}$. Es significativo, por su ubicación geográfica, que una pieza muy similar proceda de El Castillete (Reinosa, Cantabria), aunque en este caso la hebilla sea rectangular ${ }^{42}$.

La necrópolis de Pamplona ha ofrecido cinco placas más. Los tres primeros ejemplares ${ }^{43}$ tienen en común su pertenencia al grupo de placas rígidas con decoración geométrica calada. Consideradas por $\mathrm{H}$. Zeiss como de filiación romana ${ }^{44}$, fueron luego relacionados por $\mathrm{P}$. Palol con el círculo burgundio ${ }^{45}$. Más recientemente, G. Ripoll ha preferido relacionarlas con las

35 M. A. Mezquíriz, Necrópolis visigoda, cit. pág. 114.

36 E. James, The Merovingian Archaeology, cit. pág. 113.

37 Compte-rendu de Patrick Perin de l'ouvrage d'Edward James, cit, págs. 277-187.

3x Ibidem, pág. 282. Cl. Lorren, Fibules et plaques-boucles en Normandie. Contribution à l'étude du peuplement, des échanges et des influences, de la fin du V' siècle au début du VIII" siècle. Thèse de $3^{\text {* }}$ cycle dactylographiée, Caen, 1976.

${ }^{39}$ Citado por S. Lerenter, Nouvelle approche typologique, cit. pág. 230.

${ }^{40} \mathrm{Cfr}$. E. James, The merovingian archaeology, cit., págs. 393 y ss: Catálogo D: «Buckles with enamel or paste insets», Grupo III "Triangular buckle-plates». S. Lerenter, Nouvelle approche typologique..., Grupo G: «Plaques traingulaires en émail champlevé», pág. 231.

${ }^{41}$ M. Larrieu, et alii, La nécropole merovingienne de La Turraque, cit., pág. 136.

42 F. Pérez Rodriguez, M. A. de Cos Seco, Los restos visigodos de El Castillete (Reinosa, Cantabria), Sautuola. IV, 1985, págs. 315-317, fig. 4,1 lám. I, 6.

${ }^{43}$ M. A. Mezquíriz, Necrópolis visigoda, cit., lám. V.

${ }_{44}$ H. Zeiss, Los elementos de las artes industriales, cit., pág. 141. Caballero se muestra de la misma opinión para el conjunto de los broches de cinturón de placa rígida (tanto calados como grabados), considerándolos pertenecientes "a una tradición romana o si se prefiere hispanorromana" (L. Caballero Zoreda, Arqueología tardorromana y visigoda en la provincia de Soria, Actas del I Symposium de Arqueologia Soriana, Soria, 1984, pág. 444).

45 P. Palol, Esencia del arte hispánico de la época visigoda. Romanismo y germanismo, I Goti in Occidente, Settimane di Studio del Centro Italiano sull'Alto Medioevo, Spoleto, 1965, II, pág. 55. 
piezas de influencia bizantina posteriores a Recaredo ${ }^{\text {th }}$. En cualquier caso, son frecuentes tanto en la Península ${ }^{47}$ como en la Septimania ${ }^{4 x}$.

El cuarto ${ }^{\text {t" }}$ es un ejemplo fragmentado de los denominados "broches de cinturón de placa rectangular rígida y lengüeta oval o rectangular... ${ }^{50}$. Fechadas inicialmente por $\mathrm{H}$. Zeiss en la primera mitad del siglo VI, más recientemente P. Palol ${ }^{51}$ - que resalta la semejanza de estas piezas con otras procedentes de Francia e Italia-y G. Ripoll ${ }^{52}$ prefieren retrasar su cronología a finales de esta centuria. Muy frecuente también en las necrópolis peninsulares, como lo es también el último de los broches de Pamplona (1965, lám. VI).

Vemos, en resumen, que de once broches de cinturón, seis nos remiten inequivocamente al norte de los Pirineos y cinco, en cambio, son más frecuentes en el contexto funerario peninsular. Llama la atención, no obstante, la ausencia total en Pamplona de los ejemplares más característicos de la toreútica visigoda e hispanovisigoda - broches tipo I-II y broches liriformes, fundamentalmente ${ }^{3}$.

Pero no es solamente la elevada representación porcentual de placas «merovingias» la que ha llevado a hablar del cementerio franco de Pamplona, tal y como se ha dicho ${ }^{54}$, sino que es buena parte del propio conjunto de los materiales conservados el que apunta en esta dirección $y$, en particular, la notoria presencia de armamento (tres "scramasaxes», cuatro puntas de lanza y dos puntas de flecha). Se apercibieron de ello cuantos investigadores se han ocupado de su estudio. Es conocida, en efecto, la ausencia casi total de inhumaciones con armas entre los visigodos y su frecuencia, por el contrario, en el contexto merovingio. Atención especial merecen los tres «scramasaxes» mencionados por M. A. Mezquíriz ${ }^{55}$. De los datos que presenta, llama la atención, en primer lugar, sus inusuales dimensiones: entre 41 y $75 \mathrm{cms}$. de longitud y entre 3,4 y $4,4 \mathrm{cms}$. de anchura, lo que nos ofrece ya una pista para su cronología $\operatorname{tardia}^{56}$ como más adelante veremos.

46 G. Ripoll, La necrópolis visigoda de El Carpio de Tajo (Toledo), Madrid, 1985, pág. 60.

${ }^{47}$ Cfr. H. Zeiss, Die Grabfunde, cit., láms. 14-15; M. Almagro, Materiales visigodos del Museo Arqueológico de Barcelona. Las hebillas de cinturón de bronce, MMAP, XI-XII, 1950-1951, págs. 13 y ss. (lám. IV). Véanse también los paralelos citados por M. A. Mezquíriz en Berlanga de Duero, Alarilla, Deza, Palazuelos, Herrera de Pisuerga, etc. (Necrópolis visigoda de Pamplona, cit., pág. 111).

${ }^{48} \mathrm{Cfr}$. Actes des IX' journées d'Archéologie Mérovingienne: Gaule mérovingienne et monde méditerranéen. Exposition: Les derniers romains en Septimanie. IV'-VIII' siècles, Lattes, 1988, págs. 218 221.

${ }^{49}$ M. A. Mezquiriz, Necrópolis visigoda, cit., lám. VI.

${ }^{50} \mathrm{G}$. Ripoll, La necrópolis visigoda, cit., pág. 42.

${ }^{51}$ P. Palol, Esencia del arte hispánico, cit., pág. 56.

52 G. Ripoll, La necrópolis visigoda, cit., pág. 42.

${ }^{33} \mathrm{Ibidem}$, págs. 47-51. Cfr. las tablas tipo-cronológicas, propuestas recientemente para la toreútica visigoda e hispanovisigoda por esta investigadora, al estilo de las que en su día propusiera K. Böhner. (G. Ripoll, Problèmes de chronologie et de typologie à propos du mobilier funéraire hispano-wisigothique, Actes des IV' journées d'Archéologie Mérovingienne: Gaule mérovingienne et monde méditerranéen, Lattes, 1988, págs. 101 ss).

${ }^{54}$ F. Pérez Rodríguez, M. A. De Cos Seco, Los restos visigodos de El Castillete, cit., pág. 315.

${ }^{55}$ M. A. Mezquíriz, Necrópolis visigoda, cit., lám XXIV.

${ }^{56} \mathrm{Cfr}$. los estudios de W. Hübener sobre el progresivo aumento de la longitud de este tipo de armas con el paso del tiempo: Materialien zur Geschichte des merowingerzeitlinchen Saxes. Ein Beitrag zu seiner Chronologie, Produktion und Distribution. Trade and Exchange in Prehistory, Studies in honoor 


\section{LA NECRÓPOLIS DE BUZAGA (ELORZ, NAVARRA)}

El nuevo yacimiento al que ahora nos referimos se encuentra ubicado en el lugar denominado Buzaga, dentro del término municipal de Elorz y a $13 \mathrm{kms}$., aproximadamente, de Pamplona. Su situación según las coordenadas geográficas registradas en la hoja 25-8 (141) del mapa 1:50.000 del Instituto Geográfico Catastral, es la siguiente: 30TXN617547315.

El 16 de febrero de 1986, J. M. Martínez Txoperena y J. M. Pastor Elorriaga localizaban, en una pequeña loma del lugar mencionado, algunos objetos metálicos que afloraban en superficie y que han alcanzado un número no desdeñable de materiales del máximo interés. El inventario de las piezas a las que hemos tenido acceso es el siguiente: 21 lanzas de tipología diversa y en distinto estado de conservación; un «scramasax» casi completo (fig. 2, b) y varios más en estado fragmentario; dos puñales (fig. 2, a); una veintena de cuchillos, todos en estado fragmentario; varias puntas de flecha; siete placas de cinturón (tres en estado fragmentario) y dos contraplacas; dos apliques escutiformes simples y uno doble; cinco hebillas arriñonadas de bronce; tres hebillas ovaladas de bronce; seis agujas escutiformes de bronce; cuatro hebillas arriñonadas de hierro; una gran hebilla de hierro con su aguja, decoradas ambas con damasquinados en plata; varias hebillas más de distinta tipología y estado de conservación; tres probables «briquets»; cinco placas dorsales de bronce; dos plaquitas con inscripción y una pequeña pieza aviforme, todo ello respondiendo, muy probablemente, a las diversas decoraciones que adornaban los "sac à main" característicos de las sepulturas femeninas; dos botones o remaches; un alfiles de bronce fragmentado con cabeza decorada; una cuenta de pasta vitrea; un punzón de hierro; cinco anillos (tres de bronce, uno de hierro y otro fragmentado de plata); 10 tachuelas; 11 lascas de sílex; una treintena de piezas dentarias humanas; varios fragmentos más, finalmente, pertenecientes a objetos de morfologia y funcionalidad indeterminados.

Estando todo ello en estudio para una publicación que daremos a luz próximamente, nos limitaremos ahora a efectuar algunas acotaciones sobre el tema que nos ocupa. Buzaga, a diferencia de Pamplona - mucho más mixtificada culturalmente - presenta rasgos mayoritaria e inequivocamente norpirenaicos. Por desgracia, los materiales que hemos podido consultar no proceden de una excavación sistemática y carecen, por lo tanto, de la contextualización imprescindible en estos casos. Trataremos, no obstante, de analizar algunos de los objetos conservados que nos parezca más significativos. Y, en esta ocasión, nos fijaremos, al igual que en Pamplona, en los broches de cinturón.

1. El modelo más frecuente (hasta cuatro ejemplares muy similares entre sí) lo constituye la placa triangular trilobulada (fig. 3, a, b, c, d) ${ }^{57}$, parecida morfológicamente a una de las piezas ya vistas en Pamplona. Como aquélla, se correspondería, por lo tanto, con el tipo 64, 1 de P. Perin. Son placas, en efecto, que ofrecen tres lóbulos o apéndices circulares (dos próxi-

of Berta Stjerngvist, Lund, Sweden, 1988; ID.: Die Langsaxe der späten Merowingerzeit, Acta Praehistorica et Archaeologica, Berlin, núm. 21, 1988; ID.: Les scramasaxes du Musée de Metz, Actes des Xe Journées Internationales d'Archéologie Mérovingienne (Metz, 20-23 octobre 1988), 1989.

57 Los dibujos que figuran en este trabajo han sido realizados por el Dr. J. Núñez Marcén, profesor del Área de Arqueología de la Universidad del País Vasco. Asimismo queremos agradecer muy especialmente a J. M. Martínez Txaperena su magnífica disposición a la hora de facilitarnos el acceso a los materiales procedentes de Burgos que, una vez estudiados, han sido depositados por él mismo en el Museo Arqueológico de Navarra. 

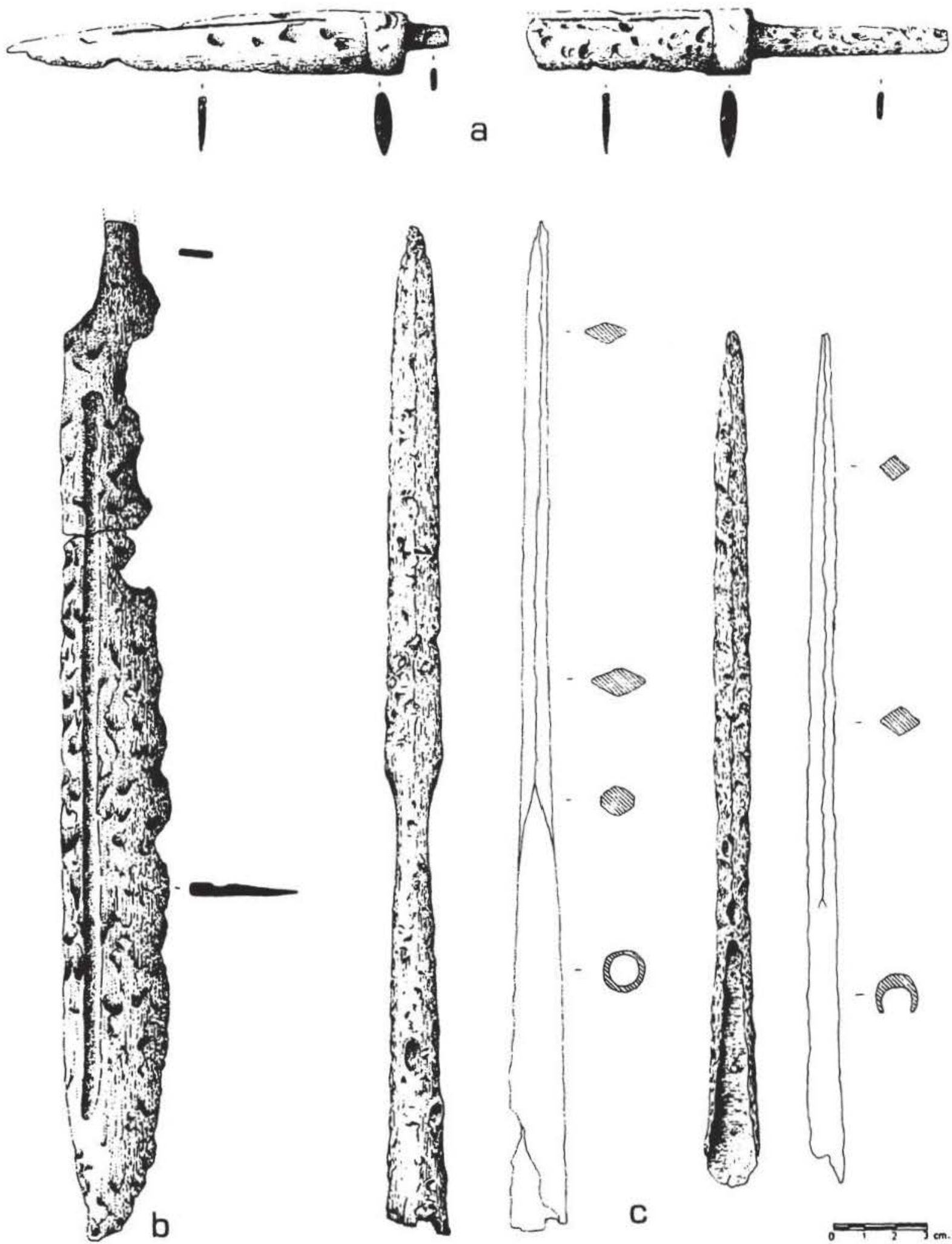

Figura 2.-Puñales (a) y uscramasax» (b) procedentes de Buzaga (Elorz, Navarra). Puntas de lanza (c) exhumadas en la necrópolis de Aldaieta (Nanclares de Gamboa, Alava). 
mos a la base el triángulo y uno en el vértice) sobre los que se fijan tres botones o remaches de carácter únicamente decorativo. Los puntos de sujeción al cuero del cinturón se sitúan en el reverso, disponiéndose el del vértice en sentido transversal a los otros dos.

Nuestros ejemplares poseen algunas peculiaridades que conviene señalar. Las placas triangulares «nórdicas», "septentrionales» o "francas" carecen con frecuencia de ornamentación alguna, a diferencia de las «aquitanas» (James: Grupo II; Lerenter: Tipo D1) perfectamente caracterizadas por una decoración especifica ${ }^{5 x}$. Se ejecuta ésta a base de una itra de metal (fundida por separado ${ }^{50}$ ) en forma de pequeño bocel sogueado que enmarca la placa rodeando los tres botones o remaches. Entre los dos de la base queda generalmente un pequeño cuadrado o rectángulo y, entre éstos y el del vértice, un trapecio ${ }^{60}$. Ambos compartimentos se ilustran generalmente con motivos incisos geométricos o zoomorfos. En el caso de los ejemplares de Buzaga, en tres de las placas - una vez realizadas a molde y antes de la fijación de los botones o remaches--, se efectuó una decoración a base de líneas ejecutadas por sucesión de puntos, representando una línea en dientes de sierra inscrita en doble banda que une los tres lóbulos o apéndices circulares (fig. 3, a, b, d). En el cuarto ejemplar (fig. 3, c) una doble banda incisa une de nuevo los tres apéndices circulares formando un pequeño rectángulo entre los dos lóbulos de la base que se decora con una cruz de San Andrés. En ambos modelos da la impresión de que se quisiera imitar la técnica de los ejemplares aquitanos antes descritos. El tipo 64, 1 de Perin, y por extensión, sus hermanas aquitanas ${ }^{61}$. se fechan a lo largo del siglo VII $^{62}$.

2. Otro ejemplar, muy frecuente también en el mundo merovingio, es el broche de cinturón de placa rígida de hebilla rectangular y lengüeta con cinco apéndices (dos a cada lado y uno en el extremo opuesto al de la hebilla) y nervadura central (fig. 4 , c). Pueden verse paralelos en La Turraque ${ }^{63}$ y Lavoye ${ }^{64}$ y vienen a fecharse a fines del siglo vı y comienzos de la centuria siguiente. G. Fingerlin realizó un estudio sobre su evolución con las variaciones morfológicas sufridas por los apéndices ( $1 .^{\circ}:$ «chefs f'öisseaux à bec crochu»; $2 .^{\circ}:$ «crochets»; $3 .^{\circ}:$ «demicercles évides»; $4 .^{\circ}:$ : «demi-cercles pleins») $)^{65}$.

3. Los tres broches que comentaremos a continuación manifiestan también una indudable filiación norpirenaica, aunque más explícitamente vinculada, quizá, a Aquitania que las que hemos descrito anteriormente. Se trata, el primero de ellos (fig. 4, a), de un ejemplar rectangular -ligeramente trapezoidal- con dos pares de botones o remaches en los laterales y un

5x Cfr. un ejemplo de ambas en M. Larrieu et alii, La nécropole mérovingienne de La Turraque, cit. págs. 134 y 135 .

${ }^{59}$ E. James, Merovingian Archaeology, cit. pág. 115.

${ }^{60}$ Ibidem, cfr. pl. 47-51.

61 Uno de los problemas fundamentales de las producciones aquitanas reside en la ausencia de una cronología precisa. Como ha señalado S. Lerenter (Nouvelle approche, cit. pág. 225) todos los intentos efectuados en este sentido se han llevado a cabo por comparación con cronologías procedentes del norte del Loira.

${ }_{62} \mathrm{M}$. Larrieu et alii, La nécropole mérovingienne de La Turraque, cit., ejemplar de la pág. 134: 1. ${ }^{\mathrm{a}}$

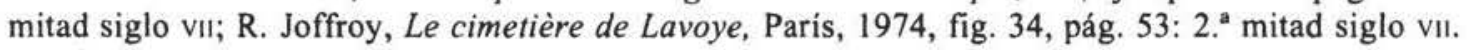

${ }^{63} \mathrm{M}$. Larrieu et alii, La néropole mérovingienne de La Turraque, cit., pág. 140.

${ }^{64}$ R. Joffroy, Le cimetière de Lavoye, cit., fig. 36, pág. 161; fig. 44, pág. 272.

${ }^{65} \mathrm{G}$. Fingerlin, Eine Schnalle mediterraner Form aus dem Reihengräberfeld Güttingen, Landkreis Konstanz, en Badische Fundberichte, 1967, 23, págs. 159-184. Tomado de P. Perin, La datation, cit. págs. $158-160$. 


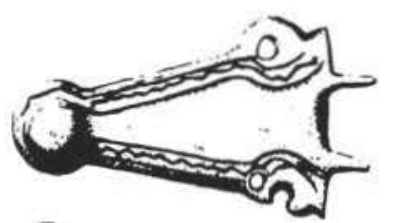

a
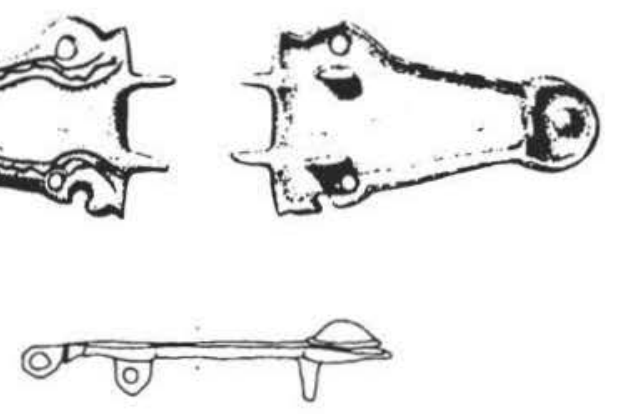

(1)
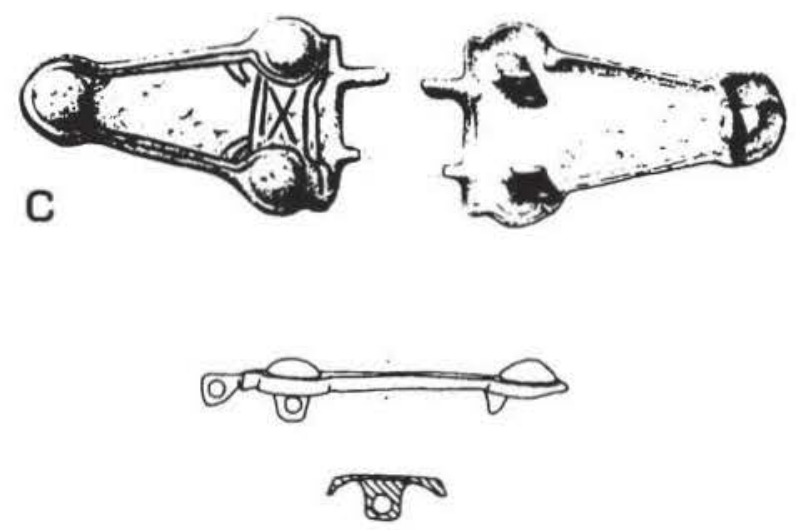

e
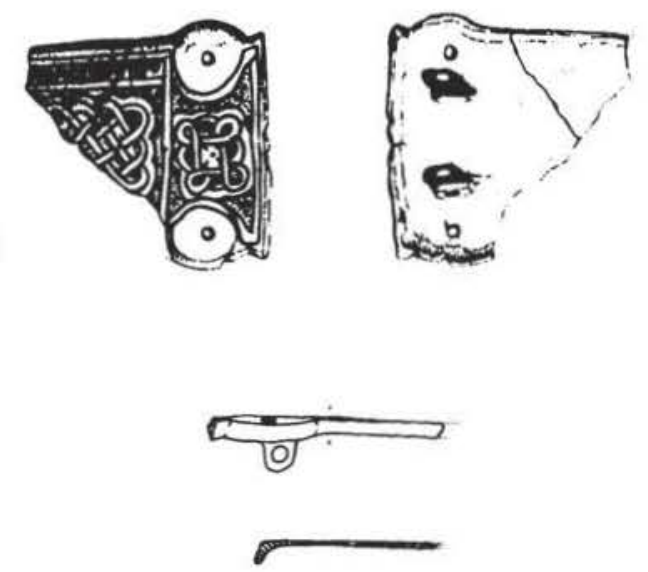

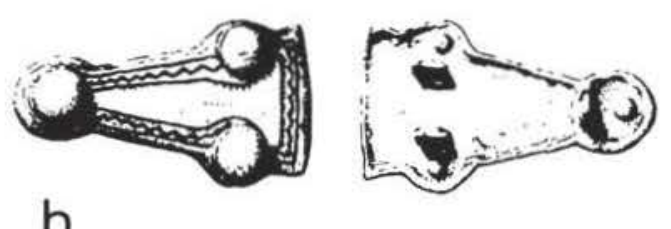

b
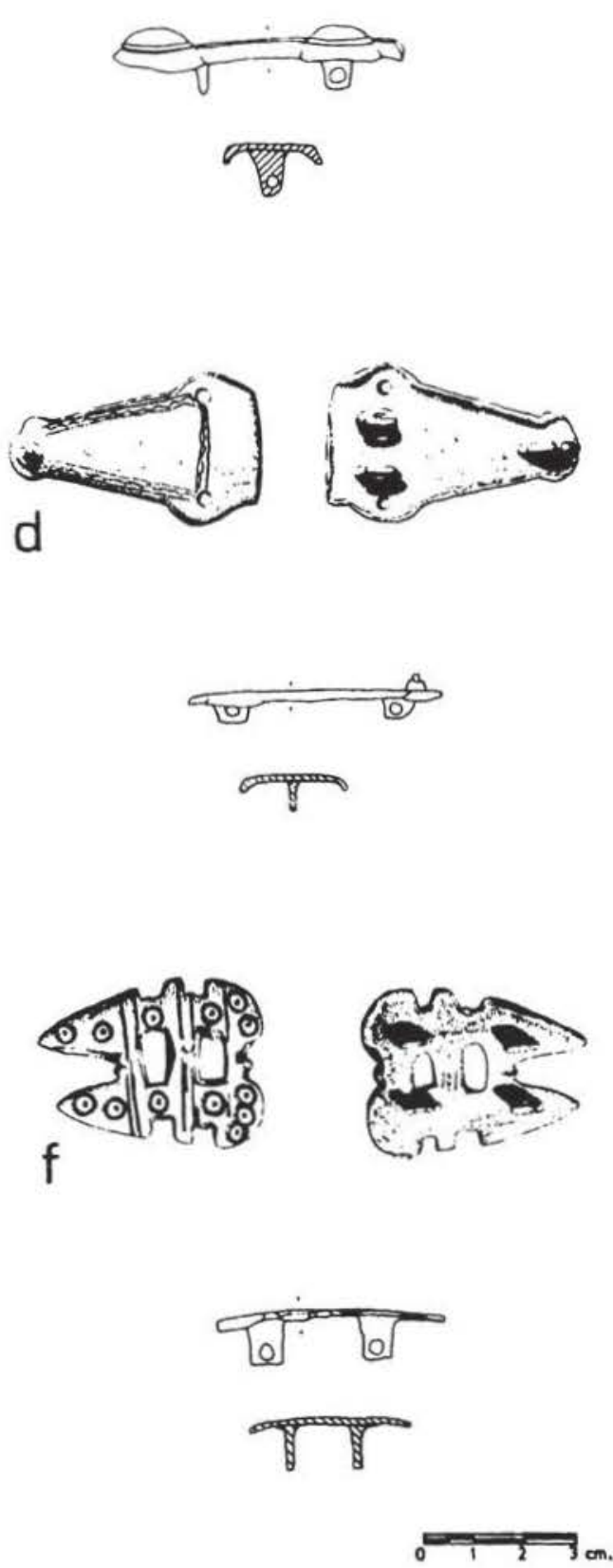

Figura 3.-Placas de cinturón (a-e) y doble remache escutiforme (f). Necrópolis de Buzaga (Elorz, Navarra). 
remache en el extremo opuesto a la hebilla, todos ellos - como viene siendo habitual en el sudoeste francés- de carácter únicamente decorativo ${ }^{66}$. Su unión a la hebilla ${ }^{67}$ se realiza por dos espigas en ambas piezas, articuladas por un pasador que no se ha conservado. La aguja es característica, también, de estos ejemplares, con una base ancha de decoración similar a la de la placa. A destacar tres de los cinco remaches adornados con pequeños círculos troquelados, con un punto central, dispuestos en forma cruciforme, y un quinto círculo similar en su centro. Existen también paralelos aquitanos en Preignan y Montegut (Gers) ${ }^{6 x}$. La decoración de la placa sigue escrupulosamente las peculiaridades más caracteristicas del ciclo aquitano: técnica a base de punzón ${ }^{\text {nt) }}$ con un fondo de puntos cubriendo gran parte del campo decorativo, medallón central en círculos concéntricos, doble banda incisa rodeando el perímetro de la placa, etc. Tipológicamente pertenece inequivocamente al grupo IB de E. James («Becked» Buckle-Plates»), y al tipo BI de S. Lerenter («Plaques trapezoidales a queue d'aronde») cuyos prototipos imita toscamente y que, según James, corresponden a un grupo local cuyo centro de producción estaria en algún lugar del Toulousin, sin paralelos fuera del sudoeste francés ${ }^{70}$. Cronológicamente ha de ubicarse en la primera mitad del siglo viI.

Nos quedan dos ejemplares por comentar, ambos desgraciadamente fragmentos, aunque no por ello pierdan interés. Del primero de ellos (fig. 4 , b) sólo conservamos la hebilla, la aguja y parte de la placa trapezoidal, con dos pequeñas espigas para su articulación con la hebilla, dos grandes botones o remaches y una decoración nuevamente característica de lo aquitano, a base de arquerias de semicirculos descansando sobre una doble línea que recorre el perímetro de la placa. En el centro un motivo peculiar ${ }^{71}$ que aparece también en la base de la hebilla. Sería fácil recoger una larga lista de paralelos iconográficos de estos semicírculos tan típicamente aquitanos: la necrópolis de Tabariane (Ariège) ofrece varios ejemplos ${ }^{72} \mathrm{y}$ resulta particularmente significativo el ejemplar del Museo de Agen procedente de Eymet-sur-Dropt (Dordogne $)^{73}$. Su adscripción tipológica no resulta del todo segura debido a su estado fragmentario. Pertenece, sin duda, al grupo I de E. James y, muy probablemente, al IB, con una cronologia por tanto de la primera mitad del siglo vil.

Otro tanto cabe decir de una placa, también fragmentada, que llama la atención por el color brillante y plateado que le confiere el baño de estaño recibido (fig. 3, e). Los dos remaches del extremo próximo a la hebilla han desaparecido. Entre ellos queda un espacio rectangular delimitado por una línea doble y, en su interior, un motivo también característico de la iconografia aquitana: el cuadrado con sus vértices constituyendo lazos unidos entre sí por semicírculos dobles ${ }^{74}$. Numerosas placas procedentes de Tabariane (Ariège), Revel, Gasailou

so Los botones o remaches - de forma cupuliforme- no cubren puntos de fijación o remaches reales. Estos - generalmente tres - se ubican más centrados en el reverso de la placa.

67 Tenemos nuestras dudas sobre nuestro acierto a la hora de elegir la hebilla que pudiera corresponder a la placa que comentamos.

6* E. James, Merovingian archaeology, cit., pág. 113.

69 Las lineas, incluso, están ejecutadas mediante una apretada sucesión de puntos.

70 E. James, Merovingian archaeology, cit., pág. 111.

$7 \mathrm{C} f$. un paralelo muy similar en una placa del Museo de Montpellier, procedente de Milhau (Aveyron). E. James, Merovingian archaeology, cit., pl. 43 y 142 .

${ }_{72}$ Ibidem, C78, C79, C80... pág. 365

${ }^{73}$ Ibidem, C12, pág. 351, pl. 129.

${ }^{74}$ Ibidem, Fig. 29 y 30, pág. 138. 

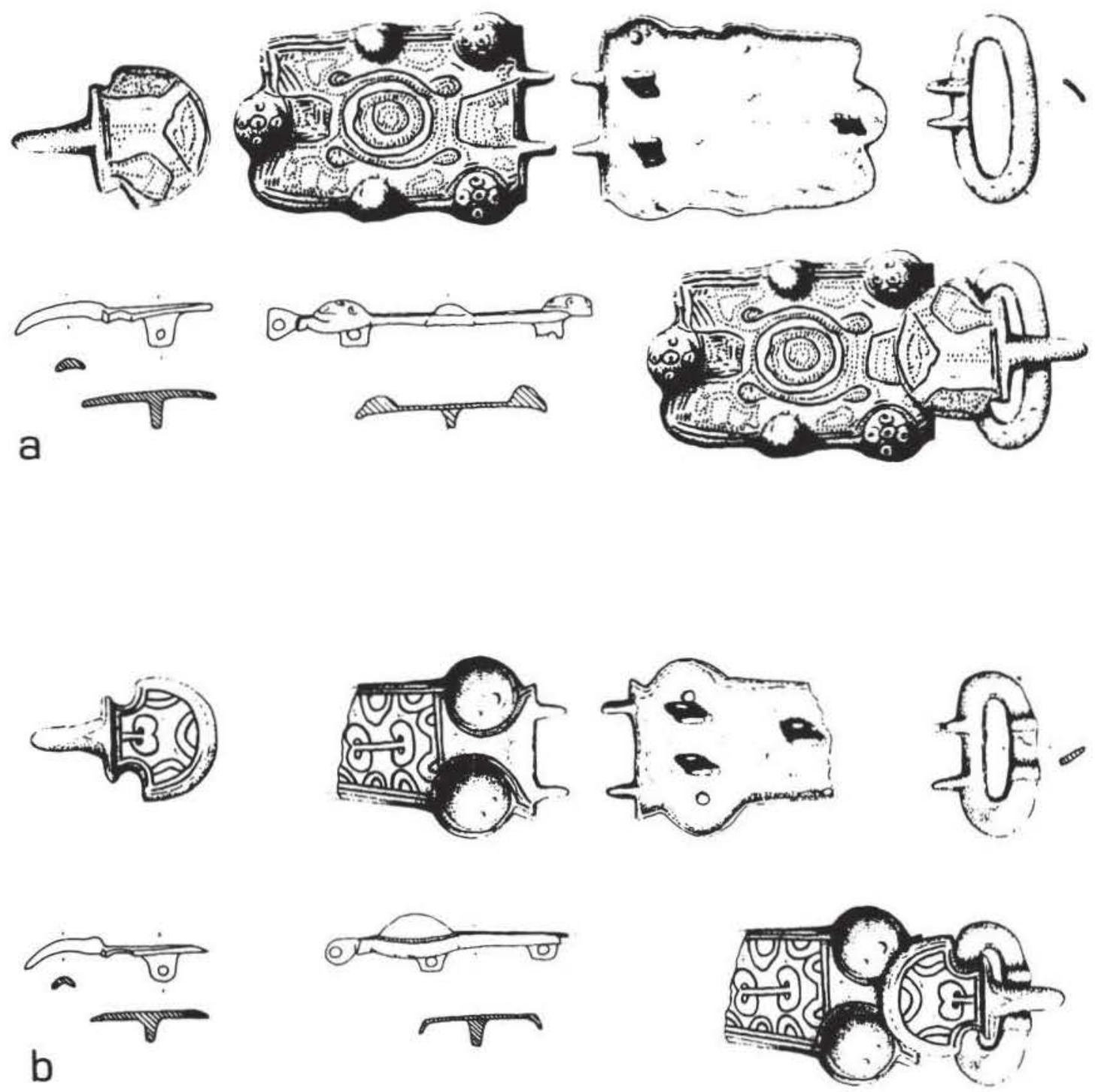

b
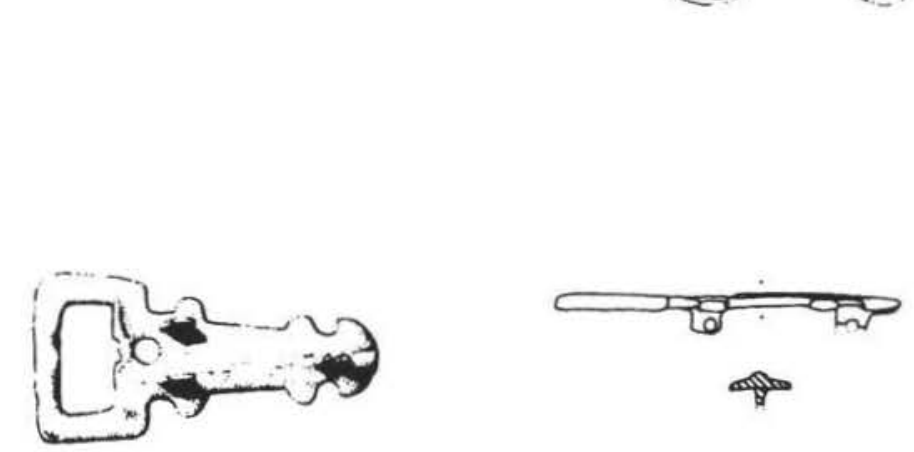

C

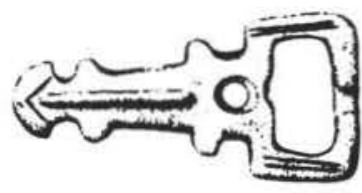

Figura 4.-Broches de cinturón de placa articulada (a-b) y rigida (c). Necrópolis de Buzaga (Elorz, Navarra). 
(Haute Garonne), Villeneuve-le-Comptal (Aude), etc. muestran motivos idénticos ${ }^{75}$. En el cuerpo central de la placa, un entrelazado de varios cabos reincide también en este mismo tipo de decoración.

El resto de los objetos recuperados en Buzaga coinciden en su origen extrapeninsular: la abundancia de armamento, los «briquets" tan caracteristicos de contextos funerarios merovingios ${ }^{3 h}$, una especie de punzones o «fiches à bélière» - objetos de funcionalidad todavía incierta y que han merecido las interpretaciones más diversas ${ }^{77}-$, ese doble aplique escutiforme (fig. 3, f) con paralelos casi idénticos en lugares de la Galia tan alejados entre sí como La Turraque (Aquitania) ${ }^{7 x}$ y Reville (Manche) ${ }^{74}$, etc. Pero, sin duda, es la abundante presencia de armamento uno de los rasgos - coincidente, por otra parte, con Pamplona - más llamativo de esta necrópolis: 21 puntas de lanza de tipologia diversa, adscribibles cronológicamente al siglo vI y comienzos de la centuria siguiente ${ }^{x u}$, un "scramasax» completo (fïg. 2 , b) fechable probablemente en la primera mitad del siglo vil y varios más en estado fragmentario, varias puntas de flecha, etc.

\section{LA NECRÓPOLIS DE ALDAIETA (NANCLARES DE GAMBOA, ALAVA)}

La necrópolis de Aldaieta, ubicada en la misma orilla del embalse artificial de UllibarriGamboa (a unos $15 \mathrm{kms}$., aproximadamente de Vitoria-Gasteiz), se halla enclavada en el término de Nanclares de Gamboa, ente adscrito administrativamente al ayuntamiento de Arrazua-Ubarrundia. Su situación, según las coordenadas geográficas en la hoja 112 (Vitoria) del mapa 1:50.000 del Instituto Geográfico y Catastral, es la siguiente: 30 TWN342532.

La existencia del yacimiento fue detectada por J. A. Apellániz González — alumno en su día y colaborador en la actualidad del Área de Arqueología de la Universidad del Pais Vascodurante el mes de septiembre del año 1987.

La necrópolis de Aldaieta ocupa una amplia extensión que se divide en dos partes, una de las cuales (sector A: orillas del pantano o playa) corre el riesgo permanente de ser cubierta por las aguas, mientras que la otra (sector B: zona de bosque) se encuentra a salvo por ubicarse en cotas superiores a las que pueden alcanzar las subidas anuales del embalse. Ya desde las mismas fechas del descubrimiento supusimos que el pantano habria deteriorado una parte importante de la necrópolis, con la pérdida definitiva de información arqueológica, tanto material (desaparición de ajuares) como histórica (ausencia de contextualización en los recuperados en superficie). No sabiamos con exactitud, sin embargo, si la pérdida (en lo que respecta a

75 Ibidem, pl. 43, fig. 12-14, pl. 133, 138, 147, etc.

${ }^{76}$ Cfr. R. Joffroy, Le cimetière de Lavoye, cit., págs. 33-34.

77 Característico, al parecer, de las sepulturas masculinas, ha recibido en la bibliografia francesa las denominaciones e interpretaciones más dispares ( «fiches à découper», "fíches à bélière», "perçoirs», «pointes», «piquoirs», "porte-équipements», «fers àiguiser», «outil de vannier» etc. (Cfr. R. Joffroy, Le cimetière de Lavoye, cit., págs. 30-32; P. Perin, La datation, cit., tipo 79, pág. 32.

${ }^{7 k}$ M. Larrieu et alii, Nécropole mérovingienne de La Turraque, cit., tumba núm. 113, pág. 114.

79 F. Escuvée, Le cimetière barbare de Réville (Manche), Caen, 1973, fig. 27.

ко Cfr. P. Perin, La datation, cit. tipos 2-6 (págs. 212, 278); R. Legoux, Analyse chronologique relative d'une vaste nécropole: l'exemple du site de Bulles (Oise), en P. Perin, La datation, cit, págs. 284 ss.; R. Joffroy, Le cimetière de Lavoye, cit., pág. 26 y fig. 11. 
la zona afectada por el pantano) era cuasi-completa, parcial o de importancia menor. En cualquiera de los tres casos merecía la pena salir de dudas dada la excepcionalidad del yacimiento. Tras la campaña de 1991, sabemos ya que la docena de enterramientos recuperados en la playa durante 1988 y 1989 eran, por desgracia, los últimos testimonios funerarios de un amplio espacio cementerial que hubo de contener numerosos enterramientos. De una aproximación hipotética a los límites de la necrópolis y de una extrapolación al sector A (playa) de la densidad de hallazgos conocidos en el sector B (bosque), puede deducirse que son varios cientos de tumbas destruidas por el embalse, lo cual nos da idea de las dimensiones e importancia del yacimiento de Aldaieta.

Hasta el presente son en torno a los noventa los enterramientos que han sido exhumados ${ }^{\times 1}$, algunos de ellos en franco estado de deterioro, y otros, por el contrario, en buen estado de conservación ${ }^{\times 2}$. Todos ellos responden, de momento, a la misma tipología de enterramientos: se trata, sistemáticamente, de tumbas en fosa simple en la que se depositó el cadáver dentro de una ataúd de madera ${ }^{\times 3}$, con un ajuar y depósito funerarios cuanto menos sorprendentes.

Entre los diversos enterramientos destaca uno sobre todos los conocidos hasta la actualidad. Se trata de la tumba núm. 28 con un material arqueológico que llama, sin duda, la atención por su abundancia y diversidad. El personaje - y no cabe duda de que lo era-- fue inhumado con dos grandes puntas de lanza junto a la tibia derecha; un hacha de combate sobre la diáfisis de la tibia izquierda; un espléndido cuenco de bronce ( «Perlrandbecken») en posición invertida con un vaso de vidrio intacto en su interior, dispuestos sobre la parte superior de ambos fémures; en la zona pelviana aparecieron un "scramasax» con restos ya mineralizados de su funda de madera y dos cuchillos; un poco más arriba, la guarnición de cinturón con una hebilla arriñonada y su aguja escutiforme, un aplique también escutiforme y dos apliques más de diversa tipologia; finalmente, sobre el pecho, un collar con cincuenta y una cuentas de ámbar y un canino de oso perforado. Este depósito funerario y este ajuar personal vienen a

*t Resulta difícil indicar con total precisión el número exacto de enterramientos, habida cuenta que, en algunos lugares de la necrópolis, los inhumados no aparecen individualizados sino formando parte de un depósito de numerosos restos óseos que sólo los antropólogos sabrán leer correctamente. Nuestra labor, como arqueólogos (con la colaboración «in situ» de un antropólogo), se ha limitado en estos casos a su registro escrupuloso - con numeración de todas las evidencias óseas sobre mosaico fotográfico y plano - y al levantamiento cuidadoso de material osteológico). Conviene recordar además, que, entre los datos recogidos en este breve artículo, están exluidos los materiales procedentes de la campaña de 1993 que han superado en importancia cuantitativa y cualitativa a los de las campañas precedentes.

*2 Las tumbas que, en la actualidad, se encuentran en el bosque (sector B) no han sido violadas en ningún caso de los conocidos hasta el momento. La poca profundidad de la mayoría de los enterramientos, sin embargo (menos de $50 \mathrm{cms}$. en muchos casos), y la acción de las raices de los árboles hace que el estado de conservación de los restos osteológicos sea delicado.

83 Sabemos de la existencia de ataúdes de madera, no porque se hayan conservados restos o trazas ligneas, sino por la abundancia de clavos que se recuperan casi sistemáticamente en todos los enterramientos. La orientación escrupulosa de las cotas y la orientación de todos los clavos, nos ha permitido, incluso, restituir varias posibilidades de construcción de estos ataúdes. En Aldaieta llama la atención, sin embargo, la entraordinaria cantidad de clavos recogidos en algunos enterramientos, muy superior a cuantos ejemplos conocemos en la Galia o en Hispania. Sin que podamos ahora profundizar en ello y para cuestiones relacionadas con este tema (existencia o no de ataúdes o parihuelas, interpretación de los clavos en algunos casos como objetos de carácter ritual o apotropaico, etc. Cfr. A. Simmer, Le cimetière mérovingien d'Audun-le-Tiche, cit., pág. 103. 
confirmar el alto nivel y la importancia cuantitativa y cualitativa que alcanzó el colectivo que vivió durante los siglos vi y vII en este rincón del territorio alavés.

El ajuar militar puede considerarse ya único en la Península con más de 40 puntas de lanza de tipologia diversa (fig. 2, c), algunas en espléndido estado de conservación, y 22 hachas de combate (fig. 5). En un rápido inventario provisional - recordando que aún no han finalizado las excavaciones - se pueden citar, además, un "scramasax", una magnífica empuñadura en asta de ciervo decorada, la estructura metálica de un casco de cuero, 11 cuchillos, una espléndida hoz de filo dentado, un broche de cinturón con placa articulada, 17 hebillas de plata y bronce, siete agujas escutiformes, seis apliques de bronce, dos agujas, una bíbula en omega, cinco vasos de vidrio (tres de ellos completos), 10 recipientes cerámicos, dos espléndidos cuencos de bronce (completos también), varias asas de sección helicoidal y refuerzos metálicos de recipientes de madera, 23 anillos de hierro, plata y bronce (algunos de ellos espléndidos, con pasta vítrea o camafeos engastados en su cabujón), dos pendientes, cinco collares, casi dos centenares de cuentas de ámbar y pasta vítrea, más de un millar de clavos, tachuelas... y un número indeterminado de objetos de hierro y bronce de oscura funcionalidad.

Otra de las novedades importantes que deparó la campaña de 1991 se refiere a la organización interna de la necrópolis. Pensábamos hasta esa fecha que su desarrollo topocronológico era horizontal, sin superposiciones de niveles sepulcrales distintos. Pues bien, hoy estamos en condiciones de desmentir esta última afirmación, al haberse constatado distintos niveles de enterramiento de gran interés. Parece claro que los inhumados en Aldaieta lo hacian en grupos perfectamente delimitados unos de otros por amplios espacios libres. En un comienzo creíamos que estos grupos - con individuos vinculados entre sí por lazos probablemente sanguíneos o sociales - se organizaban horizontalmente en largas hileras de enterramientos (al estilo de «les cimetières par rangées» de la Galia). Estos dos últimos años (1991-1992), sin embargo, han aparecido varios grupos que presentaban una organización peculiar. De abajo hacia arriba - es decir, en un sentido inverso al proceso de excavación - se ha observado, en uno de los casos, un primer nivel con tres enterramientos. El central, núm. 28 , era el más rico de todos ellos como si se tratara de una tumba fundacional sobre la que se organizó, a lo largo del tiempo, el «panteón» excavado. Sobre este primer nivel se superpuso un segundo también con tres enterramientos y, encima del central del segundo nivel, un tercero consistente en una inhumación infantil. Muy próximos, aunque fuera del sistema organizativo descrito, se observaban dos enterramientos más con ajuares de inferior calidad. Llama la atención que este grupo, aún disponiendo de amplio espacio en sus inmediaciones para depositar a sus fallecidos, prefiriera la peculiar disposición que hemos descrito aún a pesar del abigarramiento que conllevaba. Indudablemente la atracción del lugar fundacional fue más fuerte que otras consideraciones vinculadas a la comodidad o la mejor racionalización del espacio funerario.

Habrá que estudiar por qué unos grupos preferían la organización horizontal y otros, en cambio, la vertical, pudiéndose inferir de estas diferencias (junto a la aportación procedente del trabajo tipológico de los materiales y del estudio antropológico) importantes datos cronológicos, sociales o culturales. En la campaña de 1992, por ejemplo, ha sido significativa la confirmación de que los grupos funerarios con superposiciones aparecen únicamente en la zona oriental de la necrópolis, con los cuerpos orientados mayoritariamente en dirección S-N (cabeza al sur y pies al norte) y, en algún caso, N-S, mientras que la zona occidental la distribución de los enterramientos se desarrolla en largas hileras sin superposiciones y con orientación $\mathrm{O}-\mathrm{E}$ (cabeza al oeste y pies al este). Los ajuares muestran también diferencias significativas. 

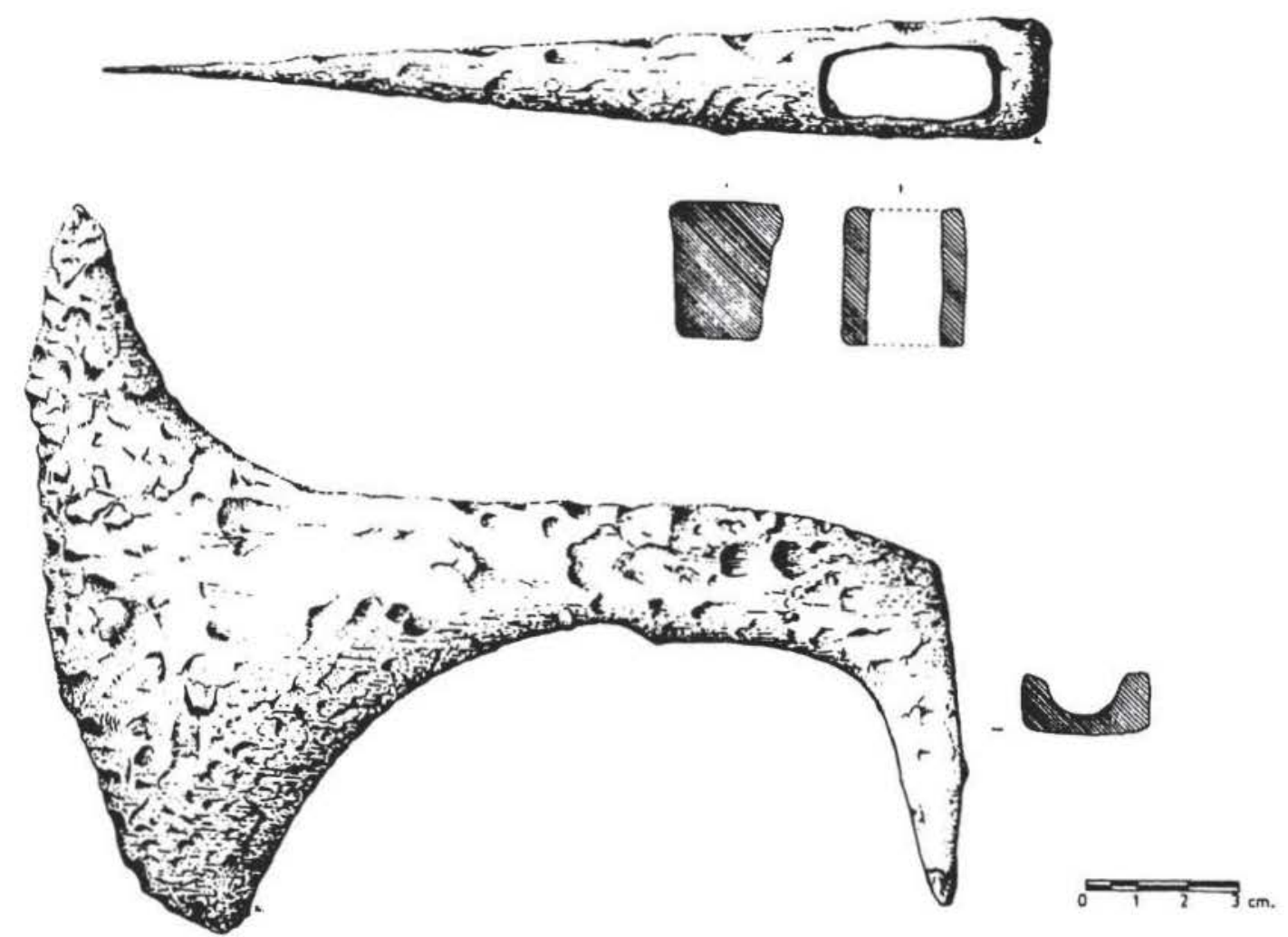

Figura 5.- Hacha de combate depositada en uno de los enterramientos de Aldaieta (Nanclares de Gamboa, Alava).

La bibliografía arqueológica tradicional habia llamado la atención, desde siempre, sobre el ordenamiento en largas hileras de muchas de las necrópolis merovingias, hasta el punto de convertir el hecho en una de sus peculiaridades más características (de ahi la denominación alemana de "Reihengräberfeld" o la francesa de "cimetières par rangées»). E. Salin llegó a considerarlo, incluso, como un rasgo típicamente germánico ${ }^{k 4}$. Los estudios más recientes, sin embargo, rechazan tales planteamientos porque, en primer lugar, no todas las necrópolis merovingias están ordenadas por hileras y, en segundo, porque tal ordenamiento existe también en necrópolis tardorromanas que no muestran ningún aporte germánico. Como señalan P. Perin y B. K Young, la disposición de los enterramientos «par rangées» puede deberse simplemente a un paralelismo entre las fosas derivado de una orientación predominante o del propio deseo de acceder a los sepulcros en muchas necrópolis en las que la densidad de los enterramientos es evidente $^{85}$. Sí que parece, en cambio, que se dio un cierto respeto por la individualidad de las

${ }^{84}$ E. Salin, La civilisation mérovingienne d'aprés les sépultures, les textes et le laboratoire (4 vols.), París, 1950-59. Aquí II, pág. 182.

${ }^{85}$ P. Perin, La datation, cit., pág. 100; B. K. Young, Paganisme, christianisation págs. 16ss; ID.: Quatre cimetières mérovingiens de l'Est de la France: Lavoye. Dieue-sur-Meuse. Mézières-Manchester et Mazerny. Etude quantitative et qualitative des practiques funéraires, Oxford (BAR International Studies, 208), 1988, nota 127, pág. 190. 
sepulturas, sea o no éste un rasgo también germánico como quiere E. Salin, lo que hace que las superposiciones - aunque se den - no sean excesivamente frecuentes, como tampoco lo son las reutilizaciones de las sepulturas ${ }^{\mathrm{x}}$. La dualidad presente en nuestra necrópolis, con grupos perfectamente diferenciados, le confieren un máximo interés. La investigación de los antropólogos, todavía en curso, puede resultar en este sentido de una importancia capital.

Otro aspecto en el que la necrópolis de Aldaieta manifiesta un alto interés, es el referido al de las costumbres funerarias, dado el grado de diversidad de los ritos que se observan bien en el aspecto relacionado con la orientación de las sepulturas, bien en el de la posición de los cuerpos, bien en el de la presencia de depósitos funerarios de indudable significativo apotropaico. Los resultados, en este sentido, son el algún caso espectaculares: dos individuos inhumanos sin cabeza, abundante presencia de denticiones humanas depositadas con intencionalidad ritual (rodeando el cráneo en un caso, alineadas cuidadosamente sobre el pecho en otro...), deposiciones de detenciones de équidos junto a las cabezas de los difuntos, etc. No es ésta, de todas maneras, una cuestión que esté de moda. Frente a los excesos, quizá, de interpretación de muchos autores clásicos de la historiografia merovingia, durante los últimos años se ha ido imponiendo un cierto excepticismo ${ }^{87}$ que pone en duda muchos de los aparentes rituales que antaño se postulaban con ardor. Recientemente, sin embargo, A. Simmer ha defendido la existencia en Audun-le-Tiche, de mutilaciones y decapitaciones rituales, presencia de numerosos objetos de carácter apotropaico, fuegos rituales y un $\sin$ fin de cuestiones que parecían haber desaparecido de la bibliografia reciente ${ }^{\mathrm{kx}}$. En el caso de Aldaieta, los antropólogos y paleopatólogos habrán de certificar la existencia - como suponemos- de esqueletos en posiciones violentadas, la presencia de modos de inhumación ciertamente sorprendentes... para tratar luego, entre todos, de contextualizar este panorama que se nos presenta lleno de complejidad.

De los resultados obtenidos, hasta el momento, en esta necrópolis, existen ciertos aspectos que merecen algún comentario: no cabe duda de que los enterramientos acogen a individuos de cualquier edad - ancianos, adultos, niños-y de ambos sexos, dato éste que, unido a la existencia - antes de la destrucción producida por las aguas del embalse- de varios cientos de enterramientos, lleva a considerar a Aldaieta no como el reflejo exclusivo de un grupo reducido de carácter militar (como se nos ha llegado a sugerir desde algunos foros), sino como el testimonio inequívoco de la existencia de un asentamiento ${ }^{89}$ importante y estable que viene a llenar

*o B. K. Young, Quatre cimetière mérovingiens, cit., pág. 148.

${ }^{87}$ Véase, por ejemplo, uno de los trabajos más significativos a este respecto: B. K. Young, Paganisme, christianisation et rites, cit.; y, más recientemente, N. GAUTHIER, Les origines chrétiennes de la Lorraine. Histoire et archéologie, Actes des Xe Journées Internationales d'Archeologie Mérovingienne. cit, págs. 65 ss.

${ }^{8 *}$ A. Simmer, Le cimetière mérovingien d'Audun-le-Tiche, cit. Cfr., en concreto, las págs. 139153. Del mismo autor, Le prélèvement des crânes dans l'Est de la France à l'époque mérovingienne, Archéologie Médiévale, 12, 1982, págs. 35 ss.

*9 Habida cuenta que la necrópolis parece responder a una población estable, desde 1989 hemos venido prospectando sistemáticamente el entorno de Aldaieta con resultados, creemos, altamente satisfactorios. Hoy en día estamos en condiciones de afirmar que el habitat relacionado con la necrópolis puede estar ubicado en un emplazamiento próximo que, rodeado de una amplia línea defensiva, domina desde lo alto el valle de Arrazua-Ubarrundia y buena parte de la Llanada alavesa. Su magnifica condición estratégica queda evidenciada en el topónimo con el que todavia su cota más alta, "Espikulatxe», de composición vasco-latina (spicula = «atalaya», «lugar de vigilancia» + aitz = "peña»). Cfr. J. A. González Salazar, Cuadernos de Toponimia, núm. 2: Toponimia Menor de Salvatierra, Vitoria, 1987. págs. $20-25$ y $32-33$. 
parcialmente ese misterioso vacío de varios siglos en la historia del Pais Vasco que tantos quebraderos de cabeza ha producido a los historiadores, generando cientos de páginas a la búsqueda de una hipotética explicación.

Que esta población poseía un fuerte componente militar queda también de toda duda. El ajuar recuperado, en este sentido, puede considerarse ya único en toda la Península superando cuanto se conocia hasta el presente. Estamos hablando de más de sesenta armas entre espadas, lanzas y hachas de combate, y todo ello únicamente en la parte conservada de la necrópolis.

No nos parece éste el momento adecuado para aventurarnos, en exceso, en disquisiciones sobre el carácter étnico-cultural de los inhumados en Aldaieta: la sorprendente e inusual presencia de armamento les aleja, desde luego, de las necrópolis visigodas e hispanovisigodas, habitualmente huérfanas - como es conocido - de este tipo de ajuares funerarios, acercándoles en cambio al mundo merovingio en el que si que resulta muy frecuente la inhumación de los varones con sus útiles militares ${ }^{90}$. La tipología de las lanzas y, sobre todo, de las "franciscas» o hachas de combate, la existencia de otros depósitos característicos del mundo merovingio como los cuencos de bronce de borde perlado o los cubos de madera con refuerzos anulares $\mathrm{y}$ asas de sección helicoidal, los rituales funerarios - tan similares en muchos casos-, etc. refuerzan esta afinidad. Nada hay, por el contrario, que recuerde los ajuares habituales de las necrópolis españolas de este período.

Todo ello, sin duda, plantea arduos problemas de interpretación histórica, obligándonos a reflexionar críticamente sobre antiguas certezas y lugares comunes de nuestra historiografia. Siempre nos había resultado dificil ubicar en la Llamada alavesa la campaña de Leovigildo contra los vascones (año 581) descrita por el Biclarense y, por lo tanto, nos resistíamos a admitir las habituales reducciones de "Victoriaco» con Vitoria, Vitoriano, Iruña o algún lugar próximo. Ya lo señalábamos antes, incluso, del descubrimiento de Aldaieta ${ }^{\text {} 1}$. Las posibilidades de tal hipótesis se reducen aún más, en opinión nuestra, porque ciertamente no parece sencillo imaginar en el escenario victorioso de Leovigildo ${ }^{42}$ a una población importante (y no visigoda) con indudable carácter militar. ¿A quién temían los inhumanos en Aldaieta? ¿De quiénes se defendían y contra quiénes luchaban? Como indicábamos en otro lugar ${ }^{43}$, es hora ya, probablemente, de poner en duda no tanto la veracidad del testimonio de Juan de Ciclara cuanto la ubicación de los acontecimientos que narra y de asumir, lógicamente, las consecuencias que de ello se deriven.

\section{ALGUNAS CONSIDERACIONES CRONOLÓGICAS A MODO DE CONCLUSIÓN}

Antes de terminar este breve trabajo, nos gustaría apuntar algunas consideraciones de carácter cronológico que habrán de tomarse en cuenta provisionalmente. Buzaga aún no ha sido objeto de una excavación sistemática y Aldaieta está todavía por concluir, sin olvidar que

${ }^{90}$ Cfr. B. K. Young, Quatre cimetières, cit., págs.

${ }^{1}$ Cfr. A. Azkárate, Arqueologia cristiana de la Antigüedad Tardia en Alava, Guipúzcoa y Vizcaya. Vitoria, 1988.

92 Recuérdese que Aldaieta se encuentra a pocos kilómetros de la capital alavesa.

${ }_{93}$ A. Azkárate El eremitismo en época visigótica. Testimonios arqueológicos... 
estudios antropológicos (absolutamente claves) están en curso de realización, que muchos materiales importantes vienen todavia siendo objeto de una restauración cuidadosa y que, en consecuencia, no han podido ser estudiados todavía con detenimiento.

Hay que recordar, además, que carecemos de hallazgos monetales que acompañen los ajuares y depósitos funerarios, que en la Península Ibérica no se conoce nada similar hasta el presente y que en las zonas aquitanas - como más próximas geográficamente - no existen demasiados estudios que puedan servirnos de referencia. Como señalaba muy recientemente todavia E. James, las fuentes arqueológicas son infinitamente inferiores en cantidad y calidad en el sudoeste que en las demás regiones de la Galia merovingia, siendo habitual la inexistencia de sepulturas ricas en ajuares, la ausencia de excavaciones sistemáticas, etc. ${ }^{94}$. Es por ello por lo que, en esta primera aproximación, hayamos recurrido a tablas tipológicas y propuestas cronológicas mucho más septentrionales.

1. Llama la atención en Aldaieta la abundancia de hebillas arriñonadas con su aguja escutiforme. Son 17 las recuperadas hasta el momento, además de siete agujas escutiformes también y varios remaches de la misma tipología. Todo ello mayoritamente en bronce —en algún caso estañado-. Estos objetos, tan característicos del ajuar personal, responden al grupo de «Bronzeschallen A6» que K. Böhner ${ }^{95}$ ubicara para Renania básicamente en su nivel III (520600 aprox.) aunque sean anteriores en origen (nivel II). En propuestas cronológicas más modernas, pertenecerian al tipo 52 de P. Perin que este autor sitúa entre las fases ABD y DEF (480-580 aprox.) dentro del estudio que efectuara para la región de Ardennes y Meuse en el Nordeste francés ${ }^{96}$ y que viene a coincidir con el que R. Legoux realizara en la necrópolis de Bulles $^{97}$ (tipo 19 de Legoux, fases ABC a CDE, es decir, de fines del siglo $v$ al 580 aprox.). La ausencia ${ }^{98}$, por otra parte, de broches de cinturón de placa tanto rígida como articulada - objetos que, salvo en algunos tipos de cronología anterior, se diversifican a partir de finales de la sexta centuria para alcanzar su esplendor en la centuria siguiente - viene a confirmar al marco temporal apuntado por las hebillas dentro del siglo vı.

La cronología del gran número de armas recuperadas, caso único en la Península, redunda en lo dicho y se orienta básicamente en la misma dirección. Las hachas de combate merovingias han merecido una datación similar en cuantos han elaborado tablas tipológicas de valor cronológico. K. Böhner las sitúa - en sus diferentes variantes formales - dentro de su nivel II (450525 aprox.) y III (525-600 aprox.) ${ }^{99}$. P. Perin (tipos 8-12) entre sus fases ABD e inicios de DEFGH (es decir, hasta finales del siglo vı e inicios del viI). Las 22 franciscas recuperadas hasta el presente en Aldaieta habría que llevarlas, por tanto, hasta finales de las sexta centuria aproximadamente.

${ }^{94}$ E. James, Les problèmes archéologiques su Sud-Ouest wisigothique et franc, Gallo-romains, wisigoths et francs, cit., pág. 149.

${ }_{95}$ K. Böhner, Die fränkischen Altertümer des Trierer Landes, Berlín, 1958, pl. 35-36.

${ }^{96}$ P. Perin, La datation, cit., pág. 216 , fig. 50 y pág. 279 , fig. 88.

${ }^{97}$ R. Legoux, Analyse chronologique relative d'une vaste nécropole: l'exemple du site de Bulles (Oise), en P. Perin, La datation, cit., pág. 284 ss. Cfr., sobre todo, H. Hübener, Eine Studie zu den Beilwaffen der Merowingerzeit, Zeitschrift für Archäologie des Mittelalters, $\mathrm{n}^{\circ}$ 8, 1980, pp. 65-127. Las hachas de Aldaieta exhumadas hasta el momento, se englobarian todas en las formas A, B y C de este autor, con cronologías similares a las expuestas en el texto.

${ }_{98}$ Salvo en un caso de un ejemplar reutilizado.

${ }^{99} \mathrm{~K}$. Böhner, Die fränkischen Altertümer, cit., pág. 18, fig. 1a. 
Otro tanto cabría decir de un porcentaje importante de las puntas de lanza recuperadas, aunque en este caso el panorama se presenta algo más complejo. La tipología es diversa y hemos de reconocer que, para algún caso, no hemos encontrado todavía paralelos evidentes. Pero una parte importante corresponde al tipo de punta lanceolada de sección losángica con enmangue tubular abierto, adscribible, según P. Perin, a sus fases ABD-DEF (hasta 570/80 aprox.). Otros tipos, sin embargo, pudieran quizá ser algo más tardios, prolongando la fecha de la necrópolis hasta entrado el siglo VII. Su aparición en los grupos que se inhuman en dirección $\mathrm{O}-\mathrm{E}$ y su ausencia entre quienes lo hacen en dirección S-N y N-S es, en este sentido, muy significativa.

Ya hemos hecho mención a la existencia en Aldaieta de dos colectivos que orientan sus muertos de distinta manera, que organizan el espacio funerario también muy distintamente y que muestran, además, en sus enterramientos ajuares con diferencias apreciables. Conocer qué hay detrás de ello es, obviamente, fundamental. Pero no sería prudente avanzar excesivas precisiones en estos momentos estando, como estamos, a la espera de los resultados que ofrezcan diversos análisis en curso y que pudiera obligarnos a matizar posteriormente algunas apreciaciones. Tampoco nos parece poco lo que avanzamos: en las proximidades de Aldaieta (Nanclares de Gamboa, Alava) vivió, de forma estable - aunque preocupada indudablemente por cuestiones militares - , una nutrida comunidad de individuos a lo largo de la segunda mitad del siglo vi y de, al menos, parte del vill. Esta comunidad no responde a cánones culturales visigodos o hispanovisigodos, sino a otros de carácter norpirenaico. Esto nos parece algo indudable. Otra cuestión muy distinta que abordaremos detenidamente cuando se publique la memoria final de las investigaciones en curso pero que no podemos tocar aquí en profundidad, es la de las interpretaciones que a este importante fenómeno puedan dársele.

No obstante, resulta inevitable pensar en el año 541, con la conocida expedición de Childeberto y Clotario al Sur de los Pirineos y en la controvertida mención del Pseudo-Fredegario a los tributos que un tal Francio, duque a la sazón de Cantabria, pagó durante largo tiempo a los monarcas merovingios hasta el reinado de Sisebuto (612-621). Entre una y otra fecha, no habría que olvidar a los pervasores que Leovigildo expulsa de Cantabria en su campaña de 574 , su victoria parcial sobre los vascones en el $581^{100}$, la acción del duque Bladastes ese mismo año, la expedición de Thierry II y Teodoberto II en el 602 y otros puntos que se tratan con detenimiento en el trabajo de $\mathrm{K}$. Larrañaga antes mencionado.

2. Nos hemos referido antes al carácter mixtificado de la necrópolis de Pamplona y a su perduración, al menos, desde época tardorromana a período islámico. Centrándonos, no obstante, en lo tardoantiguo, parece que caben pocas dudas sobre las turbulencias políticas que hubo de vivir la capital navarra durante aquellos años. Es muy poco, sin embargo, lo que sabemos con certeza - a pesar de cuanto se ha escrito- sobre quienes ejercieron el control político en la antigua Pompaelo. Las presencias y ausencias de los obispos pamploneses en los concilios visigóticos han sido interpretados tradicionalmente como indicadores de la dependencia política intermitente de la ciudad respecto a la monarquía de Toledo, aunque ha habido

${ }^{100}$ Resulta muy elocuente que un monarca como Leovigildo tuviera que conformarse con ocupar sólo una parte de Vasconia y comprensiblemente la sorpresa que un autor tan cualificado como J. J. Sayas manifiesta a este respecto. Cfr. A. Azkárate, The Western Pyrenees during the Late Antiquity, cit. págs. 190-191. 
también quien lo haya negado ${ }^{101}$. Sea como fuere, lo cierto es que los prelados o sus representantes acuden únicamente a los Concilios durante los años $589,592,681,683$ y $693^{102}$. De una rápida observación a estas fechas, se aprecia una cierta continuidad durante dos breves periodos, 581-592 y 681-693. Parece razonable suponer, como to han hecho muchos autores, que durante esos años Pamplona girara en torno a la órbita política de Toledo. ¿Qué ocurrió, sin embargo, desde el primer Concilio de Tarragona - en el 516- hasta el 581 y en el largo lapsus existente entre el 592 y el 681 ? Sin poder responder a estas cuestiones en el breve marco de este trabajo, si nos gustaria, no obstante, insistir en algunos puntos habitualmente olvidados. M. A. Mezquiriz, apercibiéndose de la «innegable diferencia que se encuentra entre los materiales muy unitarios de las necrópolis castellanas" y los que se recuperaron en la capital navarra, recordaba que «la región de Pamplona, invadida ocasionalmente por los ejércitos francos y visigodos, mantenía relaciones tanto en el norte como en el sur, por lo que (...) creemos que desde un punto de vista étnico tal vez haya que atribuirse la necrópolis a otro pueblo, posiblemente los vascones ${ }^{103}$, que presentarían en su ajuar elementos importados por los invasores del norte de los Pirineos y de los visigodos» ${ }^{104}$. Aunque cabria efectuar algunas matizaciones a lo dicho, la cita nos sirve para recordar que la existencia en la necrópolis de Pamplona --en una proporción notable-- de elementos materiales de origen nordpirenaico ya había sido advertida hace muchos años, a pesar de la poca importancia que se le ha prestado. A diferencia de Aldaieta, sin embargo, sorprende observar entre los ajuares recuperados la escasa proporción de hebillas arriñonadas con aguja escutiforme atribuibles al siglo vi ${ }^{105}$ (solamente dos), y la existencia, en cambio, de placas de cinturón de indudable aspecto aquitano, cuya

101 A. Besga Marroquin, La situación politica de los pueblos del Norte de España en la época visigoda, Bilbao, 1983, pág. 48.

${ }^{102} \mathrm{Cfr}$. J. Vives, Concilios visigóticos e hispano-romanos, Barcelona-Madrid, 1968. No incluimos el probable Concilio celebrado en Toledo durante el reinado de Gundemaro por las dudas que su existencia ha provocado. Cfr. un trabajo reciente en el que se puede ampliar la bibliografia al respecto: A González Blanco, El Decreto de Gundemaro y la historia del siglo vil, Los visigodos, Historia y Civilización, Antigüedad y Cristianismo, III, 1986, págs. 159-169.

${ }^{103}$ No se comprende muy bien la extrañeza de F. Pérez Rodríguez y M. A. De Cos Seco (Los restos visigodos, cit., pág. 315, nota 12), cuando preguntan «con qué argumentos» se atribuye Pamplona a los vascones en el artículo de M. A. Mezquíriz, para añadir luego que «dado que buena parte de la polémica... se ha centrado más en el terreno de la denominación étnica que cabría atribuir a los inhumados que en el carácter de la realidad cultural que los ajuares patentizan, sería tal vez mejor referirnos al yacimiento como necrópolis de época hispanovisigoda con influencias merovingias» (págs. 316-317). No entendemos muy bien, sin embargo, qué realidad cultural (si hispano-visigoda o franca) se quiere expresar diciendo que una necrópolis es de época hispanovisigoda con influencias merovingias. Por otra parte, y en lo que al resbaladizo terreno de lo «étnico» respecta, nos hemos cuidado mucho en este trabajo de no entrar de lleno en este punto y no lo haremos hasta que los antropólogos finalicen su trabajo en Aldaieta. De todas formas convendría recordar, como ha sido señalado en numerosas ocasiones, que la germanización de los ajuares funerarios en un territorio no significa, por fuerza, su colonización étnica (Cfr., por ejemplo, E. James, Les problèmes archéologiques du Sud-Ouest wisigothique et franc, cit., pág. 151). Y si ello fuera cierto también el caso que nos ocupa - es solamente un supuesto, aunque razonable - ¿qué otra población esperaban encontrar los autores citados en una ciudad como Pamplona?

104 M. A. Mezquíriz, Necrópolis de Pamplona, cit., pág. 131.

105 Esta fechación sirve también para la Península Ibérica. Tal y como indica G. Ripoll, las hebillas arriñonadas con aguja escutiforme pueden estar presentes en el nivel II de su tabla tipológica. 
cronología - tal y como indicábamos más arriba - se ubica en el siglo vil. Los «scramasaxes» apuntan también hacia esta cronología y, más en concreto, a fechas avanzadas ya de la séptima centuria. "Scramasaxes" de dimensiones similares a los de Pamplona han sido fechados en la necrópolis de Audun le Tiche muy a fines del siglo vil e, incluso, a comienzos del siguiente ${ }^{106}$. En cualquier caso, convendría ubicarlos de mediados del siglo séptimo en adelante ${ }^{107}$.

3. El descubrimiento de Buzaga nos parece de una importancia fundamental. Esta necrópolis, con materiales de rasgos mayoritaria e inequívocamente aquitanos aleja, o deberia alejar, definitivamente las dudas de cualquier escéptico. Todos los ajuares recuperados poseen una homogeneidad cultural que armoniza perfectamente con la capital navarra. Su abanico temporal, sin embargo, parece más amplio que el de Pamplona, con hebillas arriñonadas, agujas escutiformes y algunas puntas de lanza adscribibles al siglo vı, un broche de cinturón de placa rígida con hebilla rectangular y lengüeta de cinco apéndices, fechable a partir de fines de la sexta centuria o comienzos de la siguiente y diversas placas de cinturón o "scramasaxes» que pueden ubicarse perfectamente a todo lo largo del siglo vII. No cabe duda, pues de que Pamplona y Buzaga prolongan la cronologia que apuntaba Aldaieta ocupando una buena parte de la centuria que se inicia de los años seiscientos en adelante.

Los acontecimientos relacionados con nuestra región que se recogen en las fuentes documentales, para este período, son numerosos y debieran articularse en una explicación que armonizara las informaciones de origen documental con aquéllas inferibles de la investigación arqueológica. Sin ningún ánimo de exhaustividad y únicamente a modo de pinceladas que esbocen algunos de los sucesos relacionados con el entorno pirenaico durante los dos últimos tercios del siglo VII, comenzaremos recordando, por ejemplo, la expedición que Dagoberto I "le dernier à s'intereser à la conquête de l'Espagne wisigothique» "'ix, realizara a Zaragoza para apoyar a Sisenando, rebelado contra Suintila (632), o los numerosos contingentes burgundios que el propio Dagoberto I reunió tres años después (635) en una expedición contra los vascones que logró, según cuentan las Gesta Dagoberti, que «toda la patria de Vasconia fuera ocupada por el ejército burgundio» antes de ser derrotada por aquellos ${ }^{109}$.

Por esos mismos años, algo especialmente grave debía estar ocurriendo en las proximidades de nuestro escenario para que las epístolas de Braulio de Zaragoza insistan en manifestar una gran inquietud por «los acontecimientos y por las turbaciones (...) que amenazan a cada

(480/90-ca. 525), pero se dan fundamentalmente en el nivel III (525-560/580). Cfr. G. Ripoll, Materiales funerarios de la Hispania visigoda: problemas de cronologia y tipologia, Gallo-romains, wisigoths et francs, cit., págs. 111-132 (113); ID., Problèmes de chronologie et de typologie à propos du mobilier funéraire hispano-wisigothique, Actes des IX Journées d'Archéologie Mérovingienne: Gaule Mérovingienne et monde Méditerranée, Musée archéologique de Lattes, 1988, págs. 101-107 (102-103).

${ }^{106} \mathrm{Cfr}$. A. Simmer, Le cimetière mérovingien d'Audun-le-Tiche (Moselle), Association Française d'Archéologie Mérovingienne (Mémoire Volume 2), París, 1988, tumba núm. 28, con un ejemplar de $73,5 \mathrm{cms}$. y tumba núm. 103 con otro de $68 \mathrm{cms}$.

${ }^{107}$ Nos queda la duda de que algunos de los catorce cuchillos citados por Mezquíriz pueda tratarse también de un "scramasax», sobre todo por las dimensiones mayores que se recogen (en torno a los 20 cms.), si bien reconocemos que no siempre es fácil realizar tal diferenciación.

${ }^{108}$ M. Rouche, L'Aquitaine, des wisigoths aux Arabes, cit., pág. 93.

109 Anno quarto decimo regni Dagoberti cum Vascones fortiter revellaverent et multas predas in regno Francorum quod Charibertus tenuerat facerint... et totam Vasconiae patriam ab exercito Burgundiae fuisset repleta (Fredegario, c. 78, pág. 65). Citado por M. Rouche, L'Aquitaine, des Wisigoths aux Arabes, cit., pág. 508, nota 47. 
momento con el naufragio» y que, según ha señalado J. Orlandis, no parece motivada por el hecho circunstancial de la deposición de Suintila, sino más bien por un inquietante estado de cosas prolongado durante bastante tiempo por el valle del Ebro ${ }^{110}$. El reinado de Chintila (636639) tampoco fue más tranquilo, tal y como reflejan las actas de los Concilios V y VI de Toledo "1" y parece como si aun hubieran empeorado las cosas en época de Chindasvinto (642653). Efectivamente, durante el reinado de este último monarca, en una carta que Braulio, Eutropio y Celso dirigen a Chindasvinto se evocan insistentemente «los peligros y ataques de los enemigos». La carta - ha señalado E. A. Thompson ${ }^{112}$ - da a entender que, además de los numerosos problemas domésticos que hubo de solventar en su reinado, el monarca visigodo hubo de enfrentarse en el año 648 a graves acontecimientos externos. Los protagonistas del suceso, significativamente, proceden del valle del Ebro.

No se puede negar, por tanto, esa sensación de inquietud, preocupación y miedo. Con el fin de ir avanzando en las probables explicaciones a todo ello, quizá deberíamos mirar de nuevo al norte de los Pirineos y, particularmente a cuanto va aconteciendo por estas fechas en el viejo solar aquitano.

Con la desaparición del enérgico Dagoberto I (638), rey de Austrasia primero (623), Neustria-Borgoña más tarde (629) y Aquitania tras el fallecimiento de Cariberto II (632), comienza un proceso de debilitamiento del poder merovingio que sabrá aprovechar el viejo particularismo aquitano para ir consolidando paulatinamente un poder político que pronto actuaría al margen del control de los reyes francos ${ }^{113}$. Este proceso, resultado - según asume comúnmente la historiografía gala - del perfecto entendimiento entre las ambiciones de los poderosos patricios provinciales y los colectivos vascones, utilizados como fuerza militar al servicio de aquellas, será lento pero imparable. Cariberto II se había visto obligado a intervenir contra ellos en el 632 y, tres años más tarde, Dagoberto I organizará de nuevo un poderoso ejército consiguiendo que, al poco (636), los vascones con Aighina, duque sajón de Burdeos, a la cabeza le prestaran juramento.

No se sabe con certeza qué ocurre en Aquitania entre el año 639 y los años 658-59, pero parece que la región vive con tensión el enfrentamiento entre dos posiciones antagónicas: la de la vieja generación de Dagoberto I, fiel a los reyes francos, por una parte, y la representada por las tendencias centrifugas, irreversibles ya, del viejo substrato aquitano. El mayordomo neustrio Ebroíno tratará, aunque inútilmente, de mantener bajo control los territorios meridionales del reino franco y, quizá, con esa intención, había concedido a Félix (658/58-672), ilustre patricio de Toulouse, el principatum sobre todas las ciudades hasta los Pirineos y sobre el pueblo de los vascones, en un acto que ha sido interpretado como una restitución del Markenkönigtum de Cariberto II (629-632) 114 . Vano intento, sin embargo, a juzgar por el cariz de

110 J. Orlandis, Historia de España. La España visigótica, Madrid, 1977, pág. 149.

"I' Cfr. J. Vives, Concilios visigóticos e hispano-romanos, cit., págs. 226-248 y, en especial, el canon XII de VI Concilio, pág. 241 o E. A. Thompson, Los godos en España, Madrid, 1971, págs. 107117.

112 E. A. Thompson, Los godos en España, cit., págs. 226-227, donde se recogen también referencias a la lápida funeraria de Oppila, noble godo muerto en un enfrentamiento contra los vascones en el 642 .

${ }^{113}$ Cfr. M. Rouche, L'Aquitaine des Wisigoths aux Arabes, cit., 1. ${ }^{\text {a }}$ Parte, cap. III: Les Vascons et la marche vers l'independence, págs. 87-109, a quien seguiremos, en adelante, en nuestras referencias sobre los acontecimientos sucedidos al norte de los Pirineos.

114 Ibidem, pág. 99. 
los acontecimientos, de los que cabe deducir que Félix pudo haber cedido a la tentación de asumir un poder político propio. "La domination de Félix sur les Vascons et son alliance avec eux a eu pour résultat de faire considérer l'ensemble aquitano-vascon comme un tout, où les montagnards basques constituent le fer de lance de cette domination. Les textes confondent souvent les Aquitains avec les Vascons... C'est donc un ensemble politique nouveau qui vient de surgir, totalmente séparé des Francs" "1'5. Su sucesor Lupo (672-?) iba a acelerar cualitativamente este proceso enfrentándose abiertamente a los francos, a pesar de vano intento de Clotario III. El proceso imparable ya, se consolidará de forma aún más evidente con Eudes: "cette principauté devient alors un exemple pour toute la Gaule méridionale, où naissent d'autres révoltes, et l'unique arbitre du conflit entre Austrasie et Neustrie,, ce que lui vaut la reconnaissance de son indépendance et le titre de regnum» ${ }^{116}$.

Cabe, razonablemente, imaginar la posibilidad de que todos estos acontecimientos pudieran haber tenido alguna relación con lo que venía aconteciendo al sur de los Pirineos y llegar a intuir, en este sentido, dónde pudieron encontrar cobijo los profugi y refugae que se citan durante los reinados de Chintila y Chindasvinto, o de dónde procedian las frecuentes devastaciones que, de manos también de refugae, se mencionan en el VIII concilio de Toledo (653). El propio Froya ha sido visto como uno de ellos, y es significativo que, en su ataque a Zaragoza 8653 ), el rebelde acudiera rodeado de contingentes vascos. Es probable también que el levantamiento de estos durante el reinado de Wamba no fuera del todo ajeno a la rebelión de Paulo en la Septimania. Así lo sugiere el propio M. Rouche, recordando el papel activo jugado por Lupo y sus vascones-aquitanos en los acontecimientos ${ }^{117}$.

Estos hechos nos llevan a replantear una antigua cuestión sobre el posible entendimiento entre los vascones de ambos lados de los Pirineos, espinoso tema éste que no ha resultado del agrado de la mayoría de los historiadores y que, sin embargo, nos atrevemos a proponer de nuevo - como hipótesis de trabajo- a la luz de los nuevos datos arqueológicos. El negarlo argumentando que «las actuaciones vasconas no necesitan el montaje común de un mecanismo complejo», que "son primarias e instintivas» y que, en definitiva, "cada parte vive su propio reto" " 118 , conduce, finalmente, a un callejón sin salida en el que la única alternativa es reconocer que «el caso vascón no es asimilable a ningún otro y resulta incluso de difícil catalogación como un problema de política exterior o como un hecho de resistencia interna. Además, aparece todavía más sorprendente el fracaso de los visigodos frente a los vascones si consideramos que este pueblo no había presentado dificultades en la época de la conquista romana de Hispania y tampoco había manifestado, que sepamos, una especial belicosidad en la etapa bajoimperial, caracterizada de suyo por las revueltas de grupos sociales. La falta de información que tenemos en general sobre la organización interna de los vascones y sobre los diversos grupos humanos que los forman nos impide explicar de modo satisfactorio su actitud en la época visigoda» ${ }^{119}$.

115 Ibidem.

116 Ibidem, págs. 108-109.

117 Cfr. también las interesantes reflexiones de J. J. Sayas al respecto (Euskal Herria y los pueblos germánicos, II Congreso Mundial Vasco. Congreso de Historia de Euskal Herria, Bilbao, 1988, I, págs. 399-400).

118 Ibidem, pág. 396.

119 J. J. Sayas, La búsqueda visigoda de la unidad territorial y el caso vascónico, Veleia, 5, 1988, pág. 206. 
Antes de seguir con ello, volvamos, sin embargo, a los sucesos protagonizados por Froya. «Esta intervención - apuntan Barbero y Vigil- revela que los vascones, además de ser independientes en la región de los Pirineos, tenian una organización y una fuerza que les hacia capaces de tomar parte en la vida de naciones mucho más poderosas que ellos» "211. Pero ¿de dónde procedia esta organización y esta fuerza? Dificilmente podremos responder a esta cuestión si nos empeñamos reiteradamente en imaginar a los vascones como un extraño colectivo de montañeses bárbaros y salvajes, caracterizados, además, por la actitud - un tanto extravagante, sin duda - de reunirse periódicamente para medir sus fuerzas con sus vecinos.

Hubo de existir algo más, pero ¿qué? ¿Qué es lo que ocurre para que los vascones, un pueblo que «no había presentado dificultades en la época de la conquista romana de Hispania y tampoco había manifestado, que sepamos, una especial belicosidad en la etapa bajoimperial» se transforme radicalmente en tan poco tiempo? Estamos convencidos de que no es posible que estas comunidades pirenaicas fueran capaces de hacer cuanto se dice de ellas sin una red de núcleos defensivos estables, sin un armamento eficaz y periódicamente renovable, sin unos medios materiales adecuados, sin "algo" que fuera "catalizador» y que generase motivaciones, que decidiera las prioridades, que tomase las decisiones... Pensamos que este «elemento catalizador" hay que buscarlo en el "factor aquitano", en ese largo proceso que culmina con la creación de un poder político nuevo en el que lo "vascón» y lo «aquitano» se desdibujan, diluyéndose entre sí, en los propios cronicones merovingios. Este proceso se consolida ${ }^{121}$ precisamente en el norte de los Pirineos, cuando en el sur se vive momentos dificiles y se teme a enemigos foráneos que, sin embargo, se sienten muy próximos geográficamente.

Proponemos, pues, como hipótesis de trabajo, que se replantee la existencia de un sólida realidad vasco-aquitana que, aunque centrada básicamente el sudoeste de los territorios galos, pudo abarcar también - como sospechamos - una parte importante de las tierras que se extienden al sur de los Pirineos Occidentales. Hoy por hoy, y a modo de avance, ofrecemos como argumento la existencia de tres necrópolis ubicadas en territorios de los vascones peninsulares que participan, sin embargo, de los modos culturales que rodeaban a los vascones continentales. Tres necrópolis peninsulares con materiales que - alejándose de todo lo hispanovisigodo- en dos casos, al menos, tampoco son, empero, estrictamente "francos» sino aquitanos y fechables por esas fechas en las que Aquitania se va alejando irreversiblemente de los monarcas merovingios.

Siendo, como fueron, los vascones la «fer de lance» del poder aquitano, ¿no resulta elocuente que sea tan alto el número de armas recuperado ${ }^{122}$, que los hallazgos a los que nos referimos se ubiquen precisamente en territorios de la Vasconia peninsular y que todo ello, sin embargo, esté armónicamente integrado en un contexto cultural que nos remite de manera inequívoca al norte de los Pirineos?

t20 A. Barbero, M. Vigil, Sobre los orígenes de la Reconquista, Barcelona, 1974, pág. 64.

121 El proceso de gestación, probablemente se inició mucho antes.

122 Por encima del centenar, entre lanzas, hachas de combate, «scramasaxes» y puñales. 